\title{
Seeing and thinking in pictures: A review of visual information processing
}

\author{
Rashmi Adaval $^{1}$ (D) | Geetanjali Saluja ${ }^{2}$ | Yuwei Jiang ${ }^{3}$
}

${ }^{1}$ Carl H. Lindner College of

Business, University of Cincinnati,

Cincinnati, Ohio, USA

${ }^{2}$ University of Technology Sydney, Sydney, New South Wales, Australia

${ }^{3}$ Faculty of Business, Hong Kong Polytechnic University, Hong Kong

\section{Correspondence}

Rashmi Adaval, Carl H. Lindner College

of Business, University of Cincinnati,

Cincinnati, $\mathrm{OH}$.

Email: rashmi.adaval@uc.edu

Funding information

Hong Kong Research Grants Council, Grant/

Award Number: HKUST/GRF 640011

\begin{abstract}
Constructive and ecological theories of perception raise questions about whether visual perception is inherently data-driven (bottom-up) or interpreted in terms of higherorder cognitions (top-down). Analogies between these theoretical perspectives and the two visual systems involved in visual perception (the dorsal and ventral stream) suggest that the literature on visual information processing can be organized around two types of processes: object processing and spatial processing. Object processing involves the identification and recognition of stimuli in the environment and is shaped by existing concepts and associations in memory. It is associated with the processing of properties of objects such as color, size, shape, and pictorial details that are considered in this review. Spatial processing involves the perception of location, movement, spatial relations, and transformation of objects and other stimuli. Imagery-based processes that are used to transform marketing stimuli in order to simulate various possibilities are reviewed in this section along with individual differences in spatial and visual abilities.
\end{abstract}

\section{1 | INTRODUCTION}

The experience of seeing typically has a phenomenal character. At any conscious moment, five sense modalities simultaneously provide information that is combined to create a multisensory, perceptual experience-an experience rich in complexity, yet quotidian in nature. Although each sense modality provides an independent and unique input to the experience, it is sometimes difficult to isolate the independent effects of each sense modality because of the sheer volume of information that is processed. When walking down a busy street, for instance, individuals might not only be bombarded with the sounds of cars, buses, and the chatter of people, but also sights of traffic, people moving, billboards, and so forth. They might also feel the firmness of the sidewalk, the smell of the city, and the dankness of the air. Thus, input from all senses is combined almost instantaneously to create a subjective perceptual experience of city life. What is the nature of this perceptual experience, specifically the visual aspect of it? Do we all see things as they actually are? Or, do we see them as we are? That is, is visual processing simply the translation of colors, shapes, and other stimuli into symbols in the brain? Or, is what we perceive colored by other inputs and our existing knowledge and expectations?
Although some psychologists believe that what people see is shaped by contextual stimuli and our past experiences (Boring, 1946; Epstein, 1973; Gregory, 1993; Rock, 1977, 1983, 1997), there are others who assume that visual perception is guided by direct, data-driven processing that tells the perceiver where they are in relation to things around them (Gibson, 1966, 1979). The two theories of visual perception that developed as a result of these different views (the constructivist approach and the ecological approach) have only recently begun to be reconciled (Norman, 2002). Critical to this attempt at reconciliation has been evidence from neuroscience that suggests that there are two different visual systems that specialize in specific types of visual tasks (Jeannerod, 1997; Milner \& Goodale, 1995). The ventral system is primarily concerned with the identification of objects (e.g., "what is it?"), whereas the dorsal system allows one to react to these stimuli because of its ability to understand the spatial properties of the situated object (e.g., "where is it?"). Both systems appear to work hand-in-hand and allow us to engage with and respond to environmental stimuli.

It is worth noting that visual research in consumer behavior has fortuitously evolved along similar lines. Some of the research is focused on identification (e.g., how visual stimuli such as shapes are interpreted), whereas other research focuses more on how we use imagery to manipulate objects either spontaneously or deliberately. 
The present review uses this distinction to organize much of the consumer literature on visual processing. First, a brief historical background of the theories and the two visual systems is provided. Then, using the two systems to provide a broad organizational framework, the consumer research in each of these areas is summarized. The first section focuses on the identification of objects and their properties and includes topics such as how people process color, shapes, aesthetic elements, and composites of pictures and text. The second section focuses on how consumers manipulate images (of objects) through imagery and mental simulations in the course of thinking about different stimuli. Finally, individual differences in visual ability are discussed.

\section{2 | THEORETICAL APPROACHES TO VISUAL PERCEPTION}

Two theoretical approaches to the study of visual perception have dominated the past literature. The ecological approach, which draws largely on the theory presented by Gibson (1979), is limited to the processing of only that information that is provided by the sensory stimulation. In contrast, the constructive-inferential approach (Boring, 1946; Epstein, 1973; Gregory, 1993; Rock, 1983, 1997) focuses on processing information beyond what is directly available in the sensory stimulation (Epstein, 1995; Norman, 2002). The following section starts with a description of the ecological theory which focuses on only the sensory stimulation that the perceiver receives. The cognitive overlay provided by the constructivist approach is then discussed.

\section{1 | Ecological perspective}

The data-driven processing postulated by ecological theories (e.g., Gibson, 1979) is based on the premise that perceptual mechanisms were developed in order to assist the survival of a species as it tried to escape predators and other natural hazards. An ecological perspective typically treats perception as innate and not learned. That is, people are not trained to see. Further, sensation and perception are treated as equivalent because the input cues are all that is needed to interact with the environment. There is no need for much additional processing or interpretation.

An important aspect of Gibson's (1979) theory is the movement of the stimulus and the perceiver and the effect that this relative movement has on the optic array that flashes on the retina. The changing patterns of light provide important information about the location of the stimulus relative to the perceiver. Thus, a key aspect of Gibson's theory is that perception consists of perceiving changes over time and space in the optic array (see also Johansson, 1950). The idea is that stimuli offer the perceiver affordances. That is, each stimulus offers or provides perceivers with something that they can use. Thus, a perceiver might see flat surfaces such as land and water and be able to perceive that it is possible to stand on one and not the other because of the changing array of light.

Gibson's theory also has invariant features. For example, some aspects of the stimulus environment do not change as the stimulus moves (e.g., texture, horizon-ratio), and these invariant elements provide important information to the perceiver. For example, the horizon-ratio tells perceivers that for a 6-foot pole that is planted at varying distances in an open field, the ratio of the pole that is above and below the horizon remains the same. In an experiment conducted on aviation cadets, Gibson asked them to match the height of stakes planted at different distances in a large field with those of a series of stakes of varying heights available nearby. He showed that size perception remained invariant even though the stake was planted further away, meaning that people were able to accurately pick the correct stake even though it seemed smaller when it was farther away. Gibson suggests that observers pick up on the ratio of the size of the object sticking up above the horizon and below it, and this remains constant irrespective of the distance from the perceiver. The actual size of the retinal image is irrelevant in this type of direct perception.

It is important to note that Gibson (1979) does not subscribe to the idea that the perceptual system has a memory. Thus, there are no differences between perceiving and remembering, and the active role played by the individual in perceiving is minimal. The environment is seen as broadcasting information that the perceptual system must tune into just as the radio tunes into a broadcast (Gibson, 1966). Missing, however, is the notion that someone has to tune the radio (Michaels \& Carello, 1981).

\section{2 | Constructivist perspective}

In contrast to the ecological approach offered by Gibson (1979), the constructivist view (Boring, 1946; Epstein, 1973; Gregory, 1993; Rock, 1977) focuses on the distinction between the core, which is the basic sensory excitation that emanates from the object one is perceiving, and the context, which consists of all the other sensory information that can modify or correct the data from the core input (Titchener, 1914). To demonstrate the impact that the context has on the core perception, Holway and Boring (1941) conducted what is now considered a classic experiment. They asked participants to judge the size of a disk (core stimulus) that was presented at varying distances with more and more distance cues (context stimuli) eliminated. They found that as the background (context) cues were reduced, the poorer participants were at determining that the size of the object really had not changed. Thus, the context stimuli provided important information that modified or corrected the data of the core stimulus (Boring, 1946).

Proponents of this constructivist view have focused on understanding how the core is modified by the context (Epstein, 1973; Rock, 1977, 1983, 1997). For example, Gilchrist's (1977, 1980) experiments showed that how light a patch of color was perceived to be depended on a) whether it was placed in a dimly lit room or a brightly lit one, and b) the angle at which it was placed. Since the 
1980s, however, there has been an attempt to reconcile the ecological and constructivist views. The Gibsonian approach was seen as excellent in its analysis of the stimulation that reaches the organism but needed to be supplemented by an understanding of the processes that were the focus of the constructivist tradition (Haber, 1985; Norman, 2002). Several conceptualizations exemplify these efforts (Bennett, Hoffman, \& Prakash, 1989, 1991; Hatfield, 1988, 1990; Neisser, 1994; Norman, 2002) and have led to an examination of visual systems (Jeannerod, 1997; Milner \& Goodale, 1995) and how they might map onto visual perception theories.

\section{3 | A reconciliation using visual systems}

Research on hamsters (Schneider, 1967, 1969), monkeys (Trevarthen, 1968), and frogs (Ingle, 1973) suggested that visual analysis is carried out at two levels: A "what is it?" mode and a "where is it?" mode. Over time, this led to the identification of a ventral system, which was focused on recognition and identification of objects, and a dorsal system that was capable of transforming and using this information from an egocentric perspective (Goodale \& Milner, 1992;).

Norman (2002) summarizes neurophysiological and psychophysical studies that distinguish between the two visual systems. He suggests that both systems analyze visual input but that the analysis is for different purposes. The ventral system is primarily engaged with recognition and identification (something that requires access to stored representations), whereas the dorsal system analyzes visual input in order to facilitate visually guided behaviors such as pointing, reaching, and grasping. At times, both systems might operate to identify an object moving toward oneself; that is, the dorsal system picks up movement while the ventral system identifies the object and its size. Thus, the ventral system is a memory-based system, whereas the dorsal system does not have long-term storage of information in memory.
The two systems also differ along other dimensions. For example, the ventral system is superior at noticing finer details, whereas the dorsal system responds better to motion. The dorsal system is generally considered to be faster, although in some domains, such as reading, the ventral system can be fast as well. Ventral system processes often tend to be more conscious and are typically objectcentered, whereas dorsal system processes are more spontaneous and from an egocentric perspective. Norman (2002) makes the connections between these two visual systems and the two visual perception theories outlined earlier. He suggests a close parallel between the ventral system (which is more aligned to the constructivist theory) and the dorsal system (which is more aligned with the ecological theory).

To summarize, theories of visual perception appear to align with evidence that people use two visual systems-one to recognize and identify objects (object processing) and the other to react to them from an egocentric perspective (spatial processing). These systems work hand-in-hand to allow individuals to respond to environmental stimuli. Research on visual information processing suggests that the ventral stream (known as the "what" stream) processes objects and their features, such as color, size, and shapes, and is sensitive to pictorial details. In contrast, the dorsal stream (also known as the "where" stream) processes location, movement, spatial relations, and transformations. Thus, different brain regions appear to specialize in processing different aspects of visual information (see Figure 1). Research on how consumers process visual information and think visually can be organized in terms of these differences: Object processing is largely focused on understanding what is being perceived and the properties of these objects (e.g., color, shapes, logos, aesthetic features, and pictures), whereas spatial processing is largely focused on understanding where the object is relative to the self and its movement and transformation. The following two sections review past research using this classification.

\section{Object Processing by the Ventral Stream}

The ventral stream also known as the "what" stream processes color, texture, size, shape and pictorial details. Activation flows from the occipital lobe to the inferior temporal lobe.

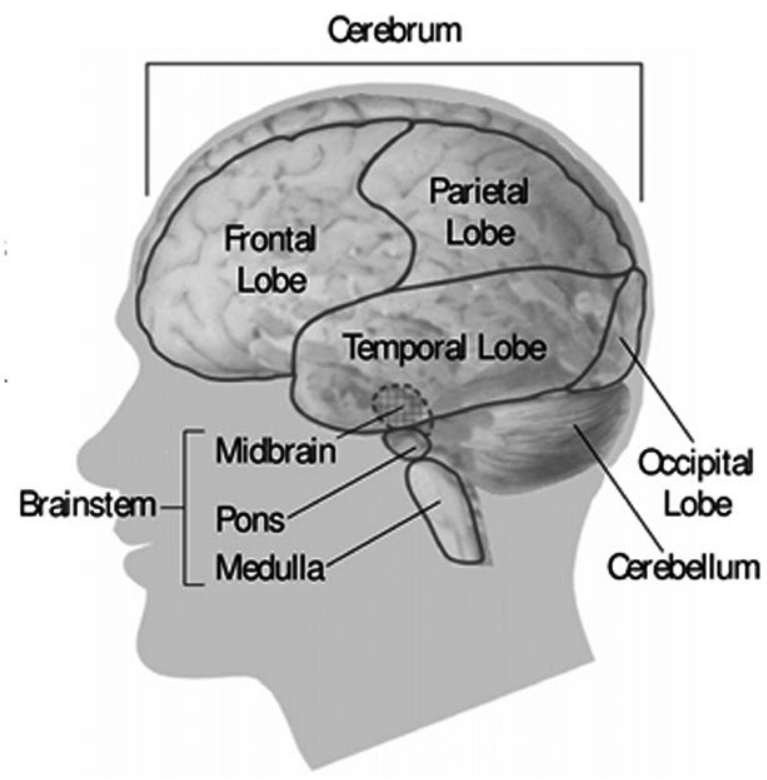

\section{Spatial Processing by the Dorsal Stream}

The dorsal stream, also known as the "where" stream processes location, movement, spatial relations and transformations. Activation flows from the occipital lobe to the posterior parietal lobe.

FIGURE 1 The dorsal and ventral pathways of the brain 


\section{3 | VISUAL INFORMATION: OBJECT PROCESSING}

Consumers usually peruse the products that are seen in the marketplace or the advertising displays that accompany them with the objective of identifying them and forming an impression of them prior to purchase. The properties of these products (e.g., their color, shape, logos, and their aesthetic elements) and the context in which they are displayed (the advertising) have been studied extensively. In the first section, research on the five major areas associated with object processing is covered: color, shape, logos, aesthetics, and the combined effects of text and visual information in communications. In each of these substantive sections, the type of effect a variable has and where along the information processing continuum is its effect localized is discussed.

\section{1 | Color}

The effects of color on consumer responses to it result from three fundamental properties: hue, chroma, and value (Thompson, Palacios, \& Varela, 1992). Hue refers to the pigment of the color (e.g., blue, red, yellow). Chroma refers to saturation or intensity, and represents the amount of pigment in the color. High-chroma colors appear more intense because of greater levels of pigment in them, whereas low-chroma colors appear duller by comparison. Value refers to the lightness or darkness of the color, as if the colors white and black have been mixed into them, with low-value colors containing more of black and high-value colors containing more of white.

\subsection{1 | Perception of color}

Although each of the aforementioned properties of color can have independent effects, color perception even at the most basic level varies such that what might appear as blue to one person could appear black to another. The news was recently filled with debates about a dress that appeared gold and white to some observers and black and blue to others. Such starkly different labels assigned to the same color are striking and presumably the result of assumptions that people make about whether the stimulus was illuminated by natural or artificial light or whether it was in a shadow versus not (Wallisch, 2017). The brain continuously adjusts for light and sometimes these adjustments are insufficient, leading to differences in perception.

Change in the amount of color in the surroundings also impacts color perception. Welbourne, Morland, and Wade (2015) gave British participants a unique shade of yellow that tends to be stable across large populations. The same respondents evaluated the color in winter and in summer by adjusting the dial of a colorimeter until they had found the "unique yellow" that was shown to them. Although the experiment was conducted in a darkened room, the same participants identified unique yellow as two different colors when they made judgments in summer and in winter. This difference occurs because of the other shades of color and light that people are exposed in summer and winter. Thus, idiosyncratic perceptions of color could actually be the result of the conditions under which people view these colors and what they have been exposed to. The ubiquity of color in our environment has also led to the formation of associations (e.g., roses are red), and these associations can guide inferences as well as feelings. Research on these issues is described presently.

\subsection{2 | Effect of color on inferences}

The effects of color on inferential processes can be direct or indirect. Direct effects on inferences are based on simple associations that exist between a color and a product, a past purchase or a usage situation. That is, specific colors might be associated with different concepts in memory based on past exposure to them. These associations can lead to inferences about products that adopt a particular color. For example, the background color of a webpage on which a product is displayed can prime certain attributes (e.g., red/orange for safety, blue for comfort, or green for price) and lead consumers to choose the cheaper option when the background is green or the safer option when the background is red (Mandel \& Johnson, 2002). Similarly, the use of gold-colored service props in a restaurant (e.g., bill folders and table cloths) as opposed to black and white ones can make consumers think of themselves and the restaurant as high status leading to larger tips (Lee, Noble, \& Biswas, 2018).

The use of color (versus black and white) can also affect preferences and evaluations indirectly through a perception of how real or life-like the object is. Objects presented in color bear closer semblance to how they appear in reality and can be construed more concretely relative to objects presented in black and white (Lee, Deng, Unnava, \& Fujita, 2014). In studies conducted by Lee et al. (2014), not only did color presentations lead to low-level, concrete construals (and black and white presentations to high-level, abstract construals), but there were differences in the type of information that consumers attended to as well. For example, the presentation of a product (e.g., a radio) in black and white increased preference for the option that had superior primary features (e.g., favorable price, size, weight), whereas color presentation increased preference for the option with superior secondary features (esthetic design, display, etc.).

The mere presence of color, however, does not always lead to an increased preference for objects or favorable attitudes. If consumers are already motivated to process ads and are exposed to more resource-demanding (image-oriented) color ads, the use of color has little effect on attitudes. Rather, it has an impact only when consumers lack the motivation to process the ad or are exposed to a low resource-demanding (functional-oriented) advertisement (MeyersLevy \& Peracchio, 1995). Thus, even though Lee et al.'s (2014) findings suggest that color has attention-directing properties and affects how people construe color ads, the beneficial effects of color appear only when it is applied to things in which people are not interested. 


\subsubsection{Effect of color on affective reactions}

The effect of color on feelings and arousal is well understood. Ads using high-value (lighter) colors are known to increase ad liking through the mediating effect of feelings of relaxation. Similarly, ads that use high-chroma colors increase liking for the ad by generating excitement (Gorn, Chattopadhyay, Yi, \& Dahl, 1997). Applying these findings in the online domain, Gorn, Chattopadhyay, Sengupta, and Tripathi (2004) examined the effect that the color of a web page's background screen has on people's perception of its download speed. They manipulated hue, chroma, and value independently and found that a hue that promoted feelings of relaxation (blue) led to perceptions that the download was faster than did a color that did not elicit as much relaxation (yellow and red). Similarly, the perceived speed of downloads was greater for a lower-chroma color because it had a relaxing effect. These feelings of relaxation on liking spilled over to the website in general, independently of assessments of download speeds.

Color, as documented earlier in the studies by Gorn et al. (1997, 2004), can also affect the feelings that people experience. Exposure to the color red can make consumers more aggressive, increase competitiveness, and the desire to win because of increases in arousal (Bagchi \& Cheema, 2013). As a result of these feelings, the bid that consumers make in an online auction increases when red (rather than blue) is used either as part of the background or the banner. In addition, having a red background color during a negotiation decreases buyers' willingness to pay compared to a blue background color presumably because of the heightened desire to win. Such increases in arousal can also increase the likelihood that people will follow their default behavioral tendencies and become less compliant. Mehta, Demmers, van Dolen, and Weinberg (2017), for example, found that using a red (versus a white or blue) background on the chat request screen of a Dutch helpline increases the likelihood of prank chats.

Objects with saturated colors (colors that appear more pure/ bright) tend to appear larger than those that are less saturated. This is apparently because saturated colors lead to higher arousal because they capture greater attention (Hagtvedt \& Brasel, 2017). This perception has implications for consumption behavior. For example, in studies by Hagtvedt and Brasel (2017), a suitcase in a more saturated color was judged to be larger, resulting in a more positive product evaluation In a different study, participants were likely to fill up more jelly beans in a cup that had a more saturated color.

Although color rarely appears in isolation, its effects in conjunction with other sensory stimuli have only recently begun to be studied. Findings by Hagtvedt and Brasel (2016) suggest that higher sound frequencies cause consumers to pay greater attention to lighter colors. This effect is presumably because consumers focus their attention on objects whose color matches the frequency of the sound they hear. Thus, when a supermarket plays a high-frequency soundtrack in the background while customers shop, they are more likely to pick bananas from a light shelf than from a dark shelf. When a low-frequency soundtrack is played, the reverse happens; people are more likely to pick bananas from the dark shelf. Although the reason for these effects is unclear and might have to do with the optimum stimulation level the perceiver seeks, cross-modal effects involving color and sound appear to affect behavior.

In summary, the research suggests that perception of color varies not only with context, but also appear to be a function of previously stored concepts and experiences that the individual has accessible in memory. It also has physiological and behavioral effects on the perceiver. Similar effects can be observed with regard to other visual stimuli such as shapes and logos.

\subsection{Shapes}

Package shape has long been of interest to practitioners and researchers because it is not only attention-grabbing but also conveys meaning to consumers (Pieters \& Warlop, 1999). The research summarized in this section focuses exclusively on the shape of products and examines its effects on preferences and behavior. Although the reason for these effects is unclear, some research sheds light on the underlying mechanisms.

\subsection{1 | Inferences about the "right" shape}

One aspect of physical shape that has drawn the attention of researchers is rectangular shapes that follow the golden ratio. The golden ratio $\Phi$ is typically derived by a mathematical expression: $a / b=(a+b) / a=1.618$ where $a$ and $b$ represent the lengths of the sides of a rectangle. Rectangles and shapes whose sides follow this proportion $(\Phi \cong 1.618)$ are considered universally pleasing. Many notable architectural features such as the Pyramids of Giza and the Parthenon in Rome follow this proportion, as do ad layouts, products packages, and product displays. Although there is a strong preference for rectangles following this ratio, some researchers have concluded that people actually prefer a range of rectangles, from $\sqrt{ } 2(1.414)$ to $\sqrt{ } 3(1.732)$ that include $\Phi$ (Benjafield, 1976; McManus, 1980; Piehl, 1978; Plug, 1976; Svensson, 1977).

Raghubir and Greenleaf (2006; see also Greenleaf \& Raghubir, 2008) examined several different product categories (e.g., business cards, humorous birthday and sympathy cards, ads in newspapers and books) and found that consumers show greater preferences for a range of ratios rather than a specific ratio. They suggest that these preferences are guided by whether the person believes that the product is intended for use in a frivolous versus a serious context (e.g., a fun party vs. a serious reception). For serious contexts, a tighter range of ratios is preferred, whereas for frivolous contexts, the range widens. This is presumably because serious contexts merit greater attention to aesthetics such as balance, harmony, and proportion, and in these types of situations products that were closer to the golden ratio are considered suitable. These results highlight the fact that perceptions and preferences for certain shapes are the product of prior expectancies and associations about what these shapes represent, and certain shapes might seem more "appropriate" in a particular context. 


\subsection{2 | Effect of shapes on consumption}

The shape of packaging often affects perceptions of quantity (Folkes \& Matta, 2004; Krider, Raghubir, \& Krishna, 2001; Raghubir $\&$ Krishna, 1999). For example, elongated containers (e.g., jars, cans, bottles) are perceived to have a higher volume than shorter ones (Raghubir \& Krishna, 1999). Further, subjects perceive that their consumption of water is higher when they use a more elongated cup and this effect is mediated by perceived volume estimates. Actual consumption is also positively influenced by the height of the container. Other studies also suggest that the number of units of a product that a consumer purchases also depends on the shape of the container even when the volume and price of the container are held constant (Yang \& Raghubir, 2005).

Although the reason for these effects is somewhat unclear, Folkes and Matta (2004) suggest that containers that attract more attention (e.g., those with unusual shapes) are perceived as having larger volume than same-sized containers that attract less attention. This is true even when the latter (same-sized containers) are taller. Such perceptions of increased volume in an unusual container decrease when consumers become habituated to the shape of the container through repeated exposure. Thus, the bias in volume estimation is likely a function of the belief that shapes that are unusual and attract more attention are a better buy.

Research on the effect of product and container shapes is relatively scant, as are the reasons why certain shapes might lead to greater perceived consumption. The effects that have been documented could have occurred because of unique designs that were considered or prior associations people have. A greater understanding of the visual processes involved in processing shapes is clearly warranted.

\section{3 | Logos}

Logos are the dominant face of a company or brand name. They can come in different shapes and colors and can consist of other types of features (e.g., boundaries, complex design elements). Even though they are relatively small, their visual elements affect the inferences that consumers make. These inferences can, in turn, affect their judgments and behavior.

\subsection{1 | Inferences about logos}

Consumers infer certain attributes about a product or company from its logo (Fajardo, Zhang, \& Tsiros, 2016; Jiang, Gorn, Galli, \& Chattopadhyay, 2016). For example, the frame around a brand logo can be perceived as protecting or confining, depending on the level of risk associated with a purchase (Fajardo et al., 2016). Which of these symbolic associations is applied can depend on consumers' need at the time of purchase. Fajardo et al. (2016) found that when consumers perceive a high level of risk, they exhibit a need for safety and security that leads them to interpret a logo frame as protective. In this case, the logo frame has a positive effect on their purchase intent. When consumers perceive a low level of risk, however, they exhibit a need for freedom and autonomy that leads them to interpret a logo frame as confining. In this case, the logo frame has a negative effect on their purchase intent.

Other work suggests that participants exposed to circular logo shapes as opposed to angular ones are likely to perceive the product (e.g., a shoe or sofa) as being more comfortable (Jiang et al., 2016). Those exposed to angular shapes, on the other hand, perceive the product to be more durable. Logo shape also affects consumers attitudes and their willingness to pay for the product. Both ratings are favorable when there is a match/consistency between the logo shape and the attribute highlighted in the ad tagline than when there is a mismatch/inconsistency.

\subsubsection{Effect of logos on evaluations and behavior}

To reiterate, consistency between the logo and taglines increases the favorability of evaluations (Jiang et al., 2016). Along similar lines, incorporating a dynamic aspect in logos in a way that increases the perception of movement (e.g., a seesaw at a diagonal versus a seesaw at horizontal/equilibrium) can also result in more favorable attitudes toward the brand because dynamic logos are more engaging compared to static ones (Cian, Krishna, \& Elder, 2014). However, when the direction of movement implied by a dynamic logo is inconsistent with attributes of the company, then brand attitudes are less favorable. That is, a forward moving logo with a traditional company or backward moving logo with a modern company are liked less well than a forward moving logo with a modern company and a backward moving logo with a traditional company.

Logo shapes can also signify stability and can influence consumption of safety-related products. Rahinel and Nelson (2016) showed that exposure to an unstable-looking logo (e.g., a triangle/ square standing on the vertex) increases participants consumption of safety-oriented products (e.g., hand sanitizer, insurance, security system, smoke detector) relative to conditions in which they are shown a stable logo (triangle/square oriented on the base). The perceived instability of the design apparently leads consumers to infer an unsafe environment which increases the value they attach to safety-oriented products.

\subsection{3 | Preference for complexity}

Researchers have also examined how a logo's complexity affects perceptions. People can take time to get used to complexities in design. Janiszewski and Meyvis (2001) compared how repeated exposure to two different types of stimuli affects preferences for them. In one condition, the brand name (e.g., Soboto Steel) was consistent with the logo (steel ball, metal tubing). In the other condition, the brand name (Fusion Consulting) was unrelated or inconsistent with the logo (steel ball, etc.). Initial exposures to both stimuli revealed that consumers do not prefer the inconsistent stimuli. However, repeated exposures increased preferences for it. Thus, complexity 
might have long-term benefits as it gives people an opportunity to elaborate on how the incongruent elements are related.

There are individual and cultural differences in preference for complexity. Asian cultures, for example, prefer elaborate, realistic (natural) designs more than their North American counterparts because the design characteristics of naturalness, harmony, elaboration, and meaning are important in creating perceptions of feng shui (Henderson, Cote, Leong, \& Schmitt, 2003; see also Henderson \& Cote, 1998). Thus, preference for complexity in visual stimuli might be culturally determined and subject to beliefs that prevail in a particular culture.

\subsection{Aesthetic elements}

It is difficult to discuss the processing of visual elements found in logos and other marketing communications without considering how people engage in and react to art. Humans have engaged in the creative process for centuries. In marketing, the aesthetics of product, package, and advertising design are given considerable attention because they affect the first impression a consumer has of the product or the company. Research on aesthetic elements has grown in the last couple of decades and provides an understanding of when and why aesthetic elements draw attention, elicit inferences, and affect behavior.

\subsection{1 | Effect of aesthetic elements on attention and inferences}

Even something as mundane as the font used in the name of the corporation reflects the thoughtful use of aesthetic elements. Such elements can draw attention and create different impressions of a corporation or a brand. For example, the typeface used by corporations to convey their name can create an impression of the corporation as pleasing, engaging, reassuring, etc. This might be useful for a bank that wants to create the impression that it is a safe place for your money (Henderson, Giese, \& Cote, 2004).

Slight differences in how the typeface is used could have significant effects on perceptions of a company. For example, consumers, who were exposed to a company with an incomplete typeface logo (one in which parts of the letters/characters were blanked out), were more likely to believe that the company was creative and innovative relative to conditions in which the typeface logo was complete. An incomplete logo apparently was more interesting, leading to inferences about creativity. Ironically, however, an incomplete logo also led consumers to think that the company was relatively less trustworthy (Hagtvedt, 2011).

\subsubsection{Effects of aesthetic elements on evaluations}

The use of art in product design and displays or art infusion as it is referred to increases luxury perceptions relative to no art conditions (Hagtvedt \& Patrick, 2008a,b). These luxury perceptions, in turn, increase overall evaluations of products. Such findings have been documented in domains as diverse as a box of kitchenware at a restaurant, an ad for bathroom fittings, as well as a photograph of a soap dispenser. Thus, the presence of visual art on products has a generally favorable effect on product evaluations. Another advantage of having art elements as part of a brand is that the fairly abstract positive connotations can spill over to brand extensions. For example, consumers evaluate brand extensions for an $\mathrm{mp} 3$ player more favorably when the ad for it contains an art work rather than a photograph (Hagtvedt \& Patrick, 2008a,b). Thus, brands associated with art are extendible to a wider variety of extension categories than brands without such art.

The luxury and class connotations afforded by art suggest that it has an overall positive effect. However, are similar findings likely when the art is not relevant to the product? Townsend and Shu (2010) found that the appearance of a financial document can impact stock evaluation and behavior. Art is typically considered irrelevant to financial documents. Yet, participants valued the company more when the annual report was aesthetically superior. This effect held even when participants were experienced investors. Participants were able to correct for this behavior, however, when the aesthetics of the report was made salient to them.

\subsection{3 | Underlying process mechanisms}

Several explanations for the effects of visual art on judgments have been suggested. One possibility is that visual art elicits inferences based on past associations and this affects evaluations. Townsend (2017), for example, showed that making a donation solicitation (e.g., an invitation to a charity gala) aesthetically appealing increased donation behavior as long as consumers perceived the high level of aesthetics to have no cost implications. In this case, highly aesthetic elements increased perceptions of organizational professionalism, leading to greater donations. However, higher cost implications increased perceptions of organizational waste, thus reducing or discouraging donations.

A second possible explanation for why art affects judgments is based on the feelings these aesthetic elements elicit (Kumar \& Garg, 2010; Reimann, Zaichkowsky, Neuhaus, Bender, \& Weber, 2010). Aesthetic elements are known to increase activation in the reward centers of the brain (Reimann et al., 2010). People also take longer to choose aesthetic/attractive packages relative to standardized/ functional ones and pay more for them even if the brand name is unknown. These findings, in conjunction, suggest that people enjoy products with art and savor the shopping experience.

A third explanation suggests that showing a preference for an aesthetic product might have implications for the self. Purchasing an aesthetically appealing product tends to affirm the consumers' sense of self (Townsend \& Sood, 2012). In their studies, Townsend and Sood used a self-affirmation task to restore consumers' sense of self prior to purchase. In this case, they were less likely to choose a highly aesthetic option. In addition, when consumers had chosen a highly aesthetic option they were more open to counter-attitudinal arguments suggesting a higher sense of self-worth. 


\subsection{4 | Awareness of preference for aesthetic elements and post-consumption behavior}

Consumers are typically not very accurate in forecasting their preferences over time. For example, consumers avoid brightly colored and boldly patterned product designs with high-arousal potential when they think about the long-term use of the product because they expect such designs to become increasingly irritating with repeated exposure (Buechel \& Townsend, 2018). They predict a rapid decrease in liking and lower product use for high-arousal-potential designs relative to low-arousal-potential designs. These predictions, however, turn out to be incorrect because when consumers actually experience the product, liking decreases more rapidly for lowarousal-potential designs than for high-arousal-potential designs. Thus, forecasters overestimate irritation and satiation from higharousal designs and as a result underestimate their liking of higharousal-potential designs over time.

Art and aesthetics in design are valued and people resist destroying it (Wu, Samper, Morales, \& Fitzsimons, 2017). This tendency has interesting implications for actual consumption. Although the product is valued more, actual consumption is likely to be lower because consumption involves destruction of something that is artistic and made with great effort. Wu et al. (2017) explored the negative impact of enhanced product aesthetics on usage and postconsumption consequences and found that participants were less likely to consume a non-durable product (e.g., toilet paper) when it was aesthetically more appealing. They were also less likely to eat and enjoy an aesthetically superior cupcake, even when they were hungry. Finally, they were more likely to experience negative affect when they had used napkins that were relatively more aesthetic. A greater perception of effort assigned to the creation of a more aesthetic product, and concerns about the subsequent destruction of this effort through consumption, mediated these results.

\subsection{Text and pictures in communications}

Experiences in the real world are largely visual (i.e., pictorial). However, marketing communications at a store typically consists of both pictorial information (e.g., images of products) as well as text information (e.g., prices, text descriptions). Similarly, advertising that is encountered out the store consists of both pictures and text. Visual marketing research has focused on understanding what grabs consumers' attention and why?

The size of an object (surface size) is an obvious indicator of the amount of attention it can command. However, the type of stimulus also has attention-drawing properties. Pictures (when compared to text) tend to draw more attention, communicate more information, and are remembered more. This is often called the picture superiority effect (Childers \& Houston, 1984). Much of the early research on advertising, which was conducted in advertising agencies, focused on how consumers evaluate ads that contain both pictures and text information. Advertising strategically vacillated between an imagebased approach (in which pictures were the dominant mode of communicating the message) or a reason-based approach (in which text was dominant) to persuade the consumer (Wyer \& Adaval, 2008).

Although pictures are generally considered superior in terms of the amount of information they convey, three important and related issues are of concern. First, the effect of pictures on the attention people pay to different aspects of a communication is unclear. The processing of these visuals is often guided by higher-order cognitions (e.g., perceptions of relevance, consumer goals), as well as the other information that is presented with it. Thus, attentional mechanisms in visual perception are important to understand. Second, the greater the attention a visual element draws, the more memorable it should be. The effect of pictures and text on memory for product and ad elements is therefore important. Third, the effect of pictures and text information in communications has yielded mixed results, and their impact on product evaluations has been relatively unclear until recently. The description of the research that follows focuses on these three issues.

\subsection{1 | Attentional mechanisms in visual processing of pictures and text}

Although larger surface sizes attract more attention, several studies find that this effect depends on the type of stimulus that is examined (Wedel \& Pieters, 2008) rather than task instructions (Pieters \& Wedel 2007). That is, increases in attention depend on whether the size of the brand, the picture or the text is varied (Peschel \& Orquin, 2013). For example, Pieters and Wedel (2004) found a significant effect of fixation likelihood and total fixation duration when the surface size of text elements in magazine ads was increased but none when the surface size of the picture or brand in the ad was increased (but see Pieters, Wedel, \& Batra, 2010). However, in a later study with feature ads, Pieters, Wedel, and Zhang (2007) showed the opposite. That is, the effect of the size of the text element was not significant but the effect of size of the brand and pictorial information was. Other researchers (e.g., Goldberg, Probart, \& Zak, 1999; Rosbergen, Pieters, \& Wedel, 1997) found such differences only among specific segments. Thus, the effects of the size of text or picture depend on the context in which the target appears, as well as individual differences. It is conceivable that people have a priori expectancies for what should be dominant in an ad versus a magazine, and deviations from these expectancies are noticed.

Studies have also examined how changing the size of one element affects how much attention people pay to other elements. Pieters and Wedel (2004), for instance, showed that increasing the size of the text elements did not impact the attention paid to a picture but reduced attention to other brand elements. Their results suggest a picture superiority effect that seems to persist even when the size of other elements is increased. Boerman, Smit, and van Meurs (2011) on the other hand show that increasing the text size decreases attention to the picture. Differences could be attributed to the larger set of ads that Pieters and Wedel examined or to other idiosyncratic 
characteristics of the stimulus. It is, indeed, the idiosyncratic characteristics of pictures that make their effect hard to study.

Some general conclusions, however, can be drawn. First, size does draw attention, as evidenced by an increase in fixation counts, fixation likelihood, and total fixation duration toward the object that is enlarged. This effect is very robust. However, the contingencies based on the target of the size manipulation (i.e., the picture, text, brand) are harder to explain. Second, increases in surface size have a non-linear (logarithmic) effect on attention. Typically, greater increases are noted when small objects are increased in size, and there is a diminishing marginal effect for size increases of large objects. Third, the salience of the object (such as color and vibrancy) can account for some but not all of the effects. Finally, the size effect on attention depends on the competitive interference posed by context elements (Janiszewski, 1998; Peschel \& Orquin, 2013).

Peschel and Orquin (2013) test several attentional models and suggest that visual scenes draw attention to the center, which becomes the focal point of attention (for evidence of this phenomenon in a retail setting, see Atalay, Bodur, \& Rasolofoarison, 2012 and Valenzuela \& Raghubir, 2009). Peripheral objects compete for attention, but the further away they are from the center, the less they compete. This is presumably because of visual acuity loss in these peripheral regions. However, increasing the size of objects in peripheral locations can compensate for some of this loss. It should be noted that these observations and studies are done under conditions when participants are gazing freely and do not have any goal in mind. Other effects are likely when people are actively seeking a certain type of information.

\subsection{2 | Memory for pictorial and verbal elements}

Greater attention can obviously enhance memory. However, this can depend on the type of information that commands attention and the processing strategy that consumers are using. Pictorial stimuli (e.g., a brand name accompanied by pictures that portray the brand) are better remembered in both the short and long term when consumers use a sensory-based strategy that is elicited by appearance-related adjectives such as shape and curvature in the instructions (Childers \& Houston, 1984). In contrast, when people process the stimuli at a semantic level (elicited by including semantic adjectives such as strong and good in the instructions), memory for pictorial stimuli is weaker. In contrast, verbal stimuli (e.g., the brand name that is written in words and not accompanied by pictures) are recalled better only in the short term and only when consumers have encoded the stimuli based on its semantic properties. In short, the way in which people process visual and text information can be a critical factor to consider when understanding these memory effects.

Another factor that is critical to the amount of attention and elaboration an ad draws is the inconsistency between the picture and the text. Houston, Childers, and Heckler (1987) combined semantically discrepant pictures and words so that the copy described an attribute that differed from the attribute pictured in the ad. They found that this copy yielded superior recall compared to instances in which the pictures and words were consistent (i.e., when the copy described the same attribute portrayed in the picture). The inconsistency in the information led to more elaborate processing that then facilitated the formation of associative linkages in memory.

A third factor that can increase memory for an ad is the variability in ad execution. This strategy is often used by companies to maintain consumers interest in the ad. Unnava and Burnkrant (1991) examined whether this strategy can increase recall. They showed participants ads for an anti-dandruff shampoo in which the execution context varied (e.g., an office context, a dating context) or remained the same. They found that participants' memory for the ad was better when they were exposed to different contexts as opposed to the same context. This improved memory was independent of the effort participants invested in processing the ad. That is, both effort and ad execution had independent effects on aided and unaided brand recall.

The previous studies suggest that inconsistency and variability both contribute to increased attention in advertising. Incongruent and unexpected information that is seen in such ads can result in more elaborate information processing and consequently to superior recall and recognition of the picture component of the ads. Such information is also coded in more detail than expected information. This greater, more extensive processing can lead to better integration of the constituent elements in the ad (Heckler \& Childers, 1992).

Individual differences also exist in how much people notice such incongruity. Women are better at identifying incongruent products (e.g., a camera with an incongruent schema/physical shape) and evaluate them more favorably, if the products are presented with other competing products (i.e., other cameras). However, even though incongruent products were noticed and evaluated more favorably, this favorable evaluation was accompanied by poor ad claim recognition. Women apparently revealed a tendency to trade off verbal recognition for visual accommodation (Noseworthy, Cotte, \& Lee, 2011). Because of these differences and the varying processing strategies that consumers use when they examine marketing communications, the effects of different types of visual elements (pictures and text) on evaluations are hard to discern.

\subsection{3 | Combined effects of pictorial and text information on evaluations}

Most marketing communications consist of visual and verbal (text) elements that can either compete for attention or work synergistically to convey the message. Edell and Staelin (1983) demonstrated that when participants are asked to look at brands in a number of unframed pictorial advertisements, their minds wander, and they tend to become distracted from the task of evaluating the brands presented in the ads. As a consequence, they have fewer evaluative thoughts-either in support of or in opposition to the claims made in the ads. Even with the few thoughts, the attributes they mention differ from those attributes the participants indicate they would use to evaluate the advertised brand. This tendency to become distracted was also evidenced by a smaller number of brand items recalled and 
the slower speed with which subjects confirmed or denied brand statements. Importantly, there were no significant differences between the pictorial framed ads and the verbal ads on any of the measures recorded. Finally, when it came to the content of the message, participants expressed more thoughts when the content was objective versus subjective.

Edell and Staelin's (1983) studies suggested that there was no advantage to having a picture in the ad. Costley and Brucks (1992) further showed that a product attribute (e.g., shoe weight) was more likely to be recalled when it was presented in pictorial form rather than text form. This superior recall was, however, unlikely to influence preference if other more diagnostic information was available or adequate. These findings collectively suggested at the time that presenting information pictorially might serve no advantage given its inability to influence behavior. However, Miniard, Bhatla, Lord, Dickson, and Unnava (1991) found that consumers' level of involvement moderated the process by which pictures affected brand attitudes and purchase intentions. Their results suggested that attitudes toward the product were only affected when consumers were exposed to affectively charged pictures (e.g., pictures with puppies) under conditions of low involvement. Under high-involvement conditions, attitudes were only enhanced when the product pictures were relevant.

These early studies typically examined single product ads. In a comparative judgment context, different results are likely because the comparison task is inherently verbal and rule-based. Hoegg, Alba, and Dahl (2010) examined how consumers reacted to conflicting pictorial and verbal information in such a comparative judgment task Participants were asked to make judgments of two brands based on a particular feature and were provided with conflicting information by pairing a less attractive picture with the superior target feature and an attractive picture with the inferior target feature. They found that participants were not influenced by attractive pictures in these situations.

In addition to the goals of the perceiver, it is important to consider the format in which the information is conveyed because the effect of pictures might depend on this format. Adaval and Wyer (1998; see also Adaval, Isbell, \& Wyer, 2007) examined how the presentation of text information (narrative vs. list) had an impact on the visual images that were presented with it. When information about two vacation destinations was conveyed in the form of a narrative, pictures had a positive effect on the impact of this information and increased evaluations. However, the same pictures interfered with the processing of the text, when the text information was presented as a list of things to do.

Some research has examined how rehearsal of information by the perceiver after it is received impacts what is retrieved from memory. Memory decrements are observed, but the type of decrement depends on the type of information that is rehearsed. Participants in Adaval and Wyer's (2004) studies were asked to observe a film of an interaction between a husband and wife. Their objective was to merely comprehend it. Later, they were asked to write their impressions of the characters involved or alternately were asked to describe the sequence of events that occurred. Communicating impressions of the actors made participants retrieve what was said, and later decreased recognition of the statements that protagonists made but had little effect on the recognition of nonverbal behaviors (i.e., other actions). However, when participants described the sequence of events that occurred in the film, their rehearsal of the actions and verbal behavior decreased recognition of both statements and nonverbal behaviors. Thus, the impact of visual and verbal information and its memorability depends on the format in which it is presented (story-like or not) and the what the individual does with it after receiving it.

This current section focused on how object processing helps in the identification and recognition of objects. Much of what people perceive visually, whether it pertains to color, shape, esthetics, or the relative influence of pictures and text in a store/ad, is the result of an interpretation of these stimuli in terms of past associations and concepts that already exist in memory. Even fundamental areas of visual perception associated with object recognition and identification (e.g., color and shape) appear to be influenced by top-down processes. The following section focuses on the spatial processing of visual stimuli and objects and shows how in some instances, such top-down processes might not operate and reactions to stimuli might be more spontaneous.

\section{4 | VISUAL INFORMATION: SPATIAL PROCESSING}

Norman (2002) notes that much of the visual information that is picked up in everyday life is processed by the dorsal system without much conscious awareness. This constant "streaming" of information and its automatic processing allows individuals to function without much deliberation about the environment around them. However, humans do possess the ability to transform this visual input at will. For example, one does not merely observe a speeding car passively; one can predict its forward motion and take evasive action if needed. As noted earlier, the dorsal stream provides dynamic information about the location of objects, their movement, and spatial relations between objects and the self. But, it is the transformation of this information that is critical not only for survival but also the pursuit of individual goals. In the consumer domain, for example, such transformations occur when consumers navigate a supermarket aisle, understand dynamic interactions in communications between individuals or in television ads, or mentally simulate the use of a product upon seeing an ad. These transformations are accomplished through the generation of mental images.

\section{1 | Transforming through imagery}

Spatial processing involves not only the ability to perceive visual stimuli but also the ability to transform the visual input that is received. For example, it is not only important to perceive the ladder propped on a sidewalk but also to transform the visual input that is received and simulate and anticipate the potential movement of others (e.g., the person on the ladder who might fall and hit pedestrians). Such transformations 
are accomplished through mental imagery. The brain receives visual input from a variety of sources, and the imprint that these visual stimuli leave behind is retrieved in some form to assist in a variety of tasks. Consumers could, for instance, generate the image of a brand they have seen (Starbucks) and consider the possibility of stopping there on the way to work. One can also generate an image of something one has not seen before (e.g., a resort one hopes to visit). Mental imagery, therefore, refers to the ability to form a quasi-perceptual image of a target stimulus even when it is not present. The tendency to think visually encompasses these sort of mental imagery processes whereby individuals generate mental images to aid them in a decision or task (for a comprehensive review of what imagery entails, the underlying processes and effects in consumer behavior, see Adaval, 2018).

Imagery and visual perception share some similarities. The same region of the brain, the striate cortex, gets activated when people generate mental images and when they perceive an object (Bartolomeo, 2002; Farah, 1989). Further, tests on patients suffering from unilateral neglect (i.e., those who are unable to see on one side and have impaired visual perception) show that these individuals also have a hard time imagining things on the side of the brain that is affected (Bisiach \& Luzzatti, 1978). However, there appear to be differences as well, because for some patients visual perception is hurt but visual imagery is not (e.g., Behrmann, Winocur, \& Moscovitch, 1992; Moro, Berlucchi, Lerch, Tomaiuolo, \& Aglioti, 2008). Accumulated findings suggest that visual perception is a bottom-up process and involves stimuli that are processed by the retina, the lateral geniculate nucleus, and the striate cortex before the signals move up to the higher regions of the cortex that are involved in imagery. Thus, the ability to generate mental images appears to involve higher-order processing.

Visual imagery typically involves visualizing objects and their movement from a first-person perspective as though the individual is taking part in the action. The output of such imagery, which is often from an egocentric view, is shown in Figure 2 as process $B$. People can also imagine things from a third-person perspective. In this case, the individual visualizes the movement from an external perspective as a spectator or an actor. This is shown as process $A$ in Figure 2. Consumer research has examined the effects of imagery from both a first- and a third-person perspective, even though this distinction has not been explicitly made in much of the work. Instructions to imagine oneself in the scene (e.g., in an ad for a spa) clearly activate imagery from an egocentric perspective. At other times, reading descriptions of a scene or viewing an ad might elicit imagery from a third-person perspective. Or, in some instances no imagery might be elicited. A summary of some of these effects is provided in the following sections (see Adaval, 2018 for a more comprehensive review of imagery effects).

\subsection{Imagery from a perspective}

Some perspective effects occur spontaneously at early stages of processing when people comprehend information. In these instances, they are often not even aware that they are viewing things from a particular perspective. Other perspective effects are more intentional and involve the perceiver deliberately taking one perspective or another in the service of some goal. In both cases, however, the mental images that are generated are either from an egocentric perspective or from a third-person perspective.

\subsection{1 $\mid$ The role of the self}

The effects of perspective taking were first identified in early studies on prose comprehension. In these studies, researchers (Black, Turner, $\&$ Bower, 1979) found that people took less time to comprehend the
FIGURE 2 Spatial processing and identification of where objects are, how they move and simulations from two perspectives (a) Third person imagery: Visualizations and simulations of external objects seen in relation
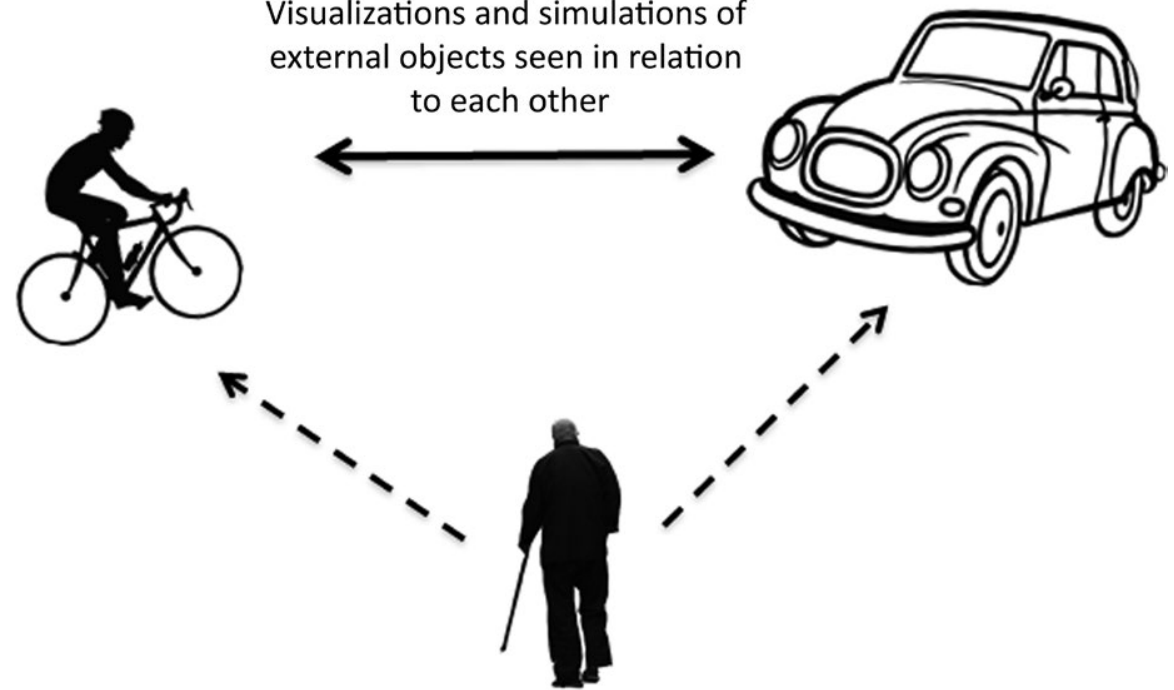

(b) First person Imagery: Visualizations and simulations conducted from an egocentric perspective 
sentence "While Mary was reading a book in her room, John came in to talk to her" than when they read "While Mary was reading a book in her room, John went in to talk to her," presumably because in the first instance the perspective adopted was that of Mary and no switch in perspective was needed to comprehend the second part of the sentence. However, these effects occurred because people spontaneously took the perspective of the protagonist in the course of reading the sentences. Later studies showed that this effect is stronger among people who have the disposition to form mental images (Jiang \& Wyer, 2009). For example, events are typically more difficult to comprehend when they are described from an unfamiliar perspective (e.g., "The man came into a prison.") than when they are described from a familiar perspective (e.g., "The man went into a prison."). However, this difference is greater for people with a disposition to form mental images and suggests that these people form an image of themselves viewing the events described and find it more difficult to do so in the former condition than in the latter.

Such spontaneous perspective taking occurs in the advertising domain as well. Imagery is typically easier to generate and is more vivid when individuals imagine themselves as the focal character in the ad (Bone \& Ellen, 1992). Such imagery has important consequences. Mandel, Petrova, and Cialdini (2006), for example, showed that when participants found it easy to imagine themselves in a story about a similar and successful other, they increased their expectations about their own future wealth and this, in turn, increased their desire for luxury brands.

Such effects of imagining oneself using a product are also evident when people encounter visual stimuli in product ads. Elder and Krishna (2012) examined how ads with subtle manipulations of product positioning could make it easier or difficult to mentally simulate the products being used from their own perspective. For example, in some conditions, they showed a cup that was oriented in a manner that would make the handle closer to the viewer's dominant hand. In other cases, it was positioned to be farther from their dominant hand. The easier it was to simulate the action of picking up the cup, the greater the purchase intent reported. However, for negative stimuli, purchase intent was lower. Such simulations of picking up and consuming the product were obviously taken from the perspective of the viewer and required some cognitive effort. In fact, when participants in Elder and Krishna's (2012) studies were given an additional task, the effect was attenuated.

Although the aforementioned papers show effects of selfimagery, they do not distinguish between the self-imagery and the more general imagery in which consumers can engage. Jiang, Adaval, Steinhart, and Wyer (2014) examined these distinctions in consumer responses to advertising. They showed that when participants had the objective of collecting information about a service (e.g., a visit to a vacation resort) and imagined themselves interacting with it, providing ads with pictures that showed the resort from different perspectives (as opposed to similar perspectives) increased evaluations. However, when participants had a goal to form a narrative of the entire experience, imagining this experience became difficult when the ad showed different perspectives, and this difficulty hurt evaluations. These effects occurred only in self-imagery conditions. This was because self-imagery required the perceiver to shift perspectives to create an overall story-a task that became more effortful in different-perspective conditions. This difficulty had a negative effect on evaluations. However, when the objective was merely to gather information, and the different pieces did not have to be integrated into a sequence as a whole, different-perspective images did not hurt evaluations.

Self-imagery may come into play in other ways. For certain types of products (e.g., clothing or performance related articles), people might have a chronic need to enhance themselves. Companies (especially clothing manufacturers) capitalize on this tendency and use smaller size labels on clothes that are, in reality, larger in size. The assumption behind this decision is that women prefer to think of themselves as a size or two smaller than their real size. Positive selfimagery (e.g., thinking of oneself as thinner) feeds into the desire to purchase products that display these lower sizes. This effect is particularly evident among consumers who are low in appearance self-esteem (Aydinoğlu \& Krishna, 2012).

\subsubsection{Ease of generating self-related imagery}

There are obviously contingencies in how easy it is to elicit selfrelated mental imagery, and this ease affects attitudes toward ads. The more fluent or easy it is to generate self-related mental imagery from an ad, the greater the favorability in attitudes for the product depicted in it. A question that advertisers have pertains to the use of models in the ad. Is the image of the product sufficient to elicit imagery or should the ads also show a person? In general, when consumers have low domain-specific self-esteem (i.e., low academic selfesteem or low appearance self-esteem), showing a product in the ad facilitates the generation of self-related mental imagery. However, when people have high domain-specific self-esteem (i.e., they are high in academic or appearance self-esteem), showing a person in the ad facilitates self-related mental imagery. These effects are presumably the result of self-enhancement and self-verification motives, respectively (Aydinoğlu \& Cian, 2014).

The tendency to imagine using a product is also enhanced when features of the context are similar to those of the situation in which the product being evaluated is normally used. In these types of situations, consumers show more favorable attitudes toward the product when their attention is focused on themselves (e.g., they are facing a mirror) because this self-focused attention facilitates the generation of self-focused imagery (Hung \& Wyer, 2011). These and other findings summarized earlier (Adaval \& Wyer, 1998; Jiang et al., 2014; Petrova \& Cialdini, 2005) suggest that ease of generating images can be affected by underlying motivations, the information format (e.g., the format, narratives), and similarity to situations that are familiar.

\subsection{3 | Psychological and physical distance from the self}

The distance of the imagined object from oneself can also affect how psychologically close it feels. Elder, Schlosser, Poor, and Xu (2017) 
suggest that sensory organs involved in assessing taste and touch are more compatible with the perception of objects close to oneself, whereas sensory organs that deal with sound and vision are relatively more compatible with the perception of objects that can be either near or far. Thus, when consumers are shown ads that ask them to imagine something involving taste and touch, they imagine it to be closer to themselves physically and psychologically. However, when they are asked to imagine something that is visual and auditory, they report that it is farther away physically and psychologically.

Imagery can also affect how people respond to the advertised benefits of new products. Marketers can communicate the benefits of new products to consumers by giving them concrete and detailed information to help them to visualize the product. However, this strategy is not always successful. Rather, it depends on the temporal perspective consumers take. That is, concrete information is beneficial when consumers' visualization of the product is retrospective and involves imagining features with which people are familiar. In contrast, abstract information is more effective when people imagine using the product in future (Zhao, Dahl, \& Hoeffler, 2014).

These effects of imagery on psychological distance are important because they affect the likelihood of an event occurring. The closer consumers feel they are to the event, the more vivid the image they are likely to generate and the greater their belief that the event will occur. Jia, Huang, Wyer, and Shen (2017), for example, showed that the physical distance from the verbal description of an event or a product influenced beliefs not only that the event was more likely to occur but also that the product described to cope with the event was more effective. The effect was not evident, however, when a clear mental image was difficult to form either because of the lack of details or because of a high cognitive load imposed on the perceiver.

\subsubsection{The functionality of self-related imagery}

People often use imagery to facilitate decision-making. That is, they might generate consumption possibilities and attempt to assess their preference for an option. In a restaurant, for example, patrons may wonder what sort of dessert to have by imagining what it tastes like. Si and Jiang (2017) found that the type of salty food participants had just eaten or imagined eating affected their perceptions of the sweetness of a dessert. Such effects were evident only when an imagery-based processing style was adopted or the salty food had actually been eaten. Thus, perceptions of a subsequent consumption opportunity (i.e., the dessert) were affected by imagery. Similarly, imagining the consumption of something many times can actually lead to satiation and reduce actual consumption (Huh, Vosgerau, \& Morewedge, 2016; but see Adaval, 2018 for a discussion of some conflicting findings in the area of consumption).

The impact of imagery on physiological responses (i.e., salivation) was demonstrated by Krishna, Morrin, and Sayin (2014). In their studies, when people were asked to imagine the odor of a food item, salivation, self-reported desire to eat and actual food consumption increased, but only when a visual mental representation of the odor referent was available. Thus, people needed a visual input (e.g., a picture of a cookie) that they could manipulate and think about before imagery elicited a physiological response.

To summarize, self-related imagery might be engaged in spontaneously or deliberately for a specific purpose. That is, it can be triggered spontaneously in the course of comprehending communications or it might be generated at will in the pursuit of some goal (e.g., information gathering, forming a narrative of an experience). Situational- and individual-level factors can enhance the tendency to engage in self-related imagery. Further, the generation of mental images of an event or a hypothetical situation can affect how close it seems. Vividness and psychological proximity can affect beliefs that the imagined event will occur and increase perceptions of the efficacy of the product associated with the event. Finally, self-related imagery can not only alter physiological responses, but also the likelihood of consuming a product.

\section{3 | Imagery elicited by pictures}

Research on imagery often conflates the effects of imagery with the effects of pictures. This is because the two appear to have similar effects. Yet, it is important to reiterate the conceptual difference: Visual perception is a process by which the eyes encode information about the stimulus (e.g., a picture, text, or a moving object), whereas imagery involves the generation of a quasi-perceptual mental image even in the absence of the stimulus. However, because people can engage in imagery while looking at something, the effects are often hard to separate.

Adaval and Wyer (1998), for example, examined the effect of pictures and self-generated images on evaluations to see whether they produced similar effects. Participants in their studies were provided with travel brochures that contained information about the places to visit either in a narrative format that specified the temporal connections of the events to be described (e.g., first you will go to $X$ and then you will go to $Y$ ) or in a list format that did not have any temporal connectors (e.g., you will go to $X$ and $Y$ ). In some cases, pictures accompanied the text, whereas in others they did not. Pictures interfered with the processing of information that was listed but facilitated the processing of information that was in the form of a narrative. However, in one experiment, instead of providing pictures, participants were asked to generate their own images and the effect of these self-generated images was the same as that of pictures that were provided. That is, these self-generated images interfered with the processing of list information but facilitated the processing of narrative information. These findings suggest that the effect of pictures and self-generated images might be similar.

Pictures that are concrete and vivid can have similar effects on attitudes as instructions to imagine. To demonstrate this, Babin and Burns (1997) showed participants one of three things: an ad containing a picture of a product in use, an ad containing a less concrete picture, and an ad without a picture. The use of a concrete picture was more effective in stimulating visual imagery and had a positive effect on attitudes. Further, ad copy that asked participants to imagine using the product also led to vivid and elaborate imagery and 
had a positive effect on attitudes. Similar effects were obtained by Petrova and Cialdini (2005), who presented participants with a vacation ad that either had an actual picture or was made to look like an abstract painting. Participants who were asked to imagine the product experience found it more difficult to do so when they saw the picture of the abstract painting, and this reduced ad persuasiveness and the likelihood of engaging in the behavior.

The research discussed thus far suggests that vivid pictures have the same effect as mental imagery. However, not all pictures generate imagery spontaneously. Subtle changes can be made to pictures to facilitate the generation of mental images and encourage mental simulations. For example, altering traffic signs and other warning signs (e.g., signs showing a school zone or a wet floor) in a subtle way to make them more dynamic (e.g., by showing children running instead of walking or showing a person falling) can elicit greater attentional vigilance and increase perceptions of risk. This, in turn, can affect behavior (e.g., braking more quickly in a simulated driving task; Cian, Krishna, \& Elder, 2015). There are many factors that can facilitate or hinder the imagery generated from pictorial stimuli. One factor is the format of the ad (Adaval \& Wyer, 1998; Thompson \& Hamilton, 2006). For example, when consumers use imagery processing, non-comparative ads are more effective than comparative ads, whereas when consumers use analytical processing, comparative ads are more effective. This difference occurs because the two ad formats are compatible with the processing modes: Imagery gets disrupted when there are distractions that arise from comparative processes and works best in the noncomparative contexts (Thompson \& Hamilton, 2006).

Imagery is also enhanced when participants are allowed to interact with visual information in some way. Schlosser (2006) compared consumers' responses to static pictures and text displayed on the web with object interactivity (e.g., where they interacted with the same object on the web by turning it around). Object interactivity facilitated the creation of vivid, internally generated recollections of the product, and this type of imagery during retrieval led to false memories about the product features.

The effects of imagery are not always positive. For example, chronic imagery vividness does not always amplify the effect of vivid information present in ads. Imagery can actually attenuate the effect of such information because people who are good imagers tend to ignore information that is obvious and look for information that is non-obvious. Thus, imagery is likely to amplify the effects of vivid information only when this is the sole information available to individuals (Pham, Meyvis, \& Zhou, 2001).

Tacit in all of these studies discussed thus far is the idea that visuals are not just perceived but that we do something with them. Some research suggests that even still photographs showing people and objects in motion lead participants to complete the motion being depicted (Freyd, 1983). Further, neurological evidence suggests that such imagery-involving movement activates the same brain regions as observing a picture of an action or the real act itself (Goebel, Khorram-Sefat, Muckli, Hacker, \& Singer, 1998; Kourtzi \& Kanwisher, 2000; O'Craven \& Kanwisher, 2000). Thus, the ability of pictures to elicit simulations is noteworthy in terms of the theories of visual perception outlined earlier. There is clearly a very dynamic, predictive component associated with visual perception, and we do not merely "see" things as they are; we see them in relation to our own physical presence and actively interact and modify what is seen. However, there are individual differences in the extent to which people imagine objects and scenes and manipulate or transform them. Thus, a discussion of visual processing would not be complete without a discussion of these individual differences.

\section{4 | Individual differences in visual processing tendencies}

There are individual differences in how responsive people are to visual stimuli, the extent to which they use pictures while solving problems, or engage in imagery. Although differences in these abilities are well known (Bartlett, 1932; Paivio, 1971; Richardson, 1977), the study of individual differences began with the simplistic categorization of people as visualizers and verbalizers. This classification distinguished people on the basis of their tendency to use mental pictures to solve problems. Paivio (1977) and Richardson (1977) developed and refined a scale (the VVQ scale) that included items such as "I often use mental pictures to solve problems." Although this scale tapped into verbal abilities, it was unrelated to performance on visuospatial tasks and also weakly correlated with the vividness of mental imagery (Alesandrini, 1981; Green \& Schroeder, 1990), raising the general question about how performance on visual tasks should be measured. Research measuring individual differences suggests that people might differ along several dimensions. These include a) performance on visuospatial tasks that require a focus on objects versus spatial characteristics, b) vividness of the images formed, and c) the tendency to use images while processing information.

\subsection{1 | Performance on visual and spatial tasks}

Recent research by Kozhevnikov and colleagues (Kozhevnikov, Kosslyn, \& Shephard, 2005; see also Borst \& Kosslyn, 2008, 2010) corroborates the idea that the visual system processes properties of objects (e.g., shape, color) differently from other spatial characteristics (e.g., location, movement, rotation). Kozhevnikov suggests that people who visualize or generate these rich mental images might actually consist of two types of individuals: object visualizers and spatial visualizers. Object visualizers typically have rich visual memories and tend to process scenes holistically. Spatial visualizers are exceptional at judging distances, relative dimensions, and velocities. They tend to examine images more analytically in different parts. Interestingly, artists appear to be better at object imagery, whereas engineers are better at spatial imagery (Blazhenkova \& Kozhevnikov, 2010).

It is interesting to note the similarities between these two groups and the two visual perception systems noted earlier. Are these different abilities the result of the overdevelopment of one system? 
Kozhevnikov and colleagues have, for instance, shown that those who are good at verbal thinking typically score average on object and spatial thinking tests. Furthermore, those who excel at object visualization do badly at spatial visualization and vice versa, suggesting that there may be a tradeoff when one engages in object and spatial visualization (Kozhevnikov, Blazhenkova, \& Becker, 2010).

For the purposes of consumer research, three groups of individuals with distinct abilities might be considered: verbalizers, spatial visualizers, and object visualizers. Each group might focus on different aspects of marketing communications. Verbalizers might be particularly adept at examining attribute information or reasoned arguments. Object visualizers might be particularly sensitive to esthetics, whereas spatial visualizers might be good at transforming images of a product and determining how to use it in multiple ways. Additional research on the implications of these different abilities is needed.

\subsection{2 | Vividness of imagery}

A scale developed by Marks (1973) measures the vividness of mental images that are formed. Petrova and Cialdini (2005) used this scale to examine not only the vividness of mental images people formed but also how accessible the output of imagery was. When products were presented using degraded pictures, imagery appeals were less effective and had negative effects on evaluations of the product.

Although the vividness of mental imagery scale predated findings about object and spatial visualizers, it needs to be considered in the context of these later findings. The two groups might differ in their ability to generate vivid images of different things. As noted earlier, artists might be able to create vivid images of objects, whereas engineers or scientists might be better able to generate vivid images of spatial models and processes. Thus, the content of what is vividly generated might differ.

\subsection{3 | Differences in processing style}

There are differences in the extent to which people use images while processing information. Childers, Houston, and Heckler's (1985) developed a style of processing scale and made a distinction between whether one was able to engage in visual imagery and a preference for it as an information processing style. Preference for a particular style of processing can, of course, be correlated with ability to imagine. However, preferences can also be primed by situational factors. The style of processing scale developed by Childers et al. (1985) shows that this disposition to engage in visual processing is uncorrelated with ability but reflects a preference for a style of processing given a situational prime (Childers \& Jass, 2002; Jiang, Steinhart, \& Wyer, 2007). Despite criticisms (Bagozzi, 2008; but see Wyer, Hung, \& Jiang, 2008; Wyer, Jiang, \& Hung, 2008), this scale is useful because it allows one to assess whether contextual factors can lead to a preference for the use of one type of processing versus another.

Although there are differences in how people process information visually and their preference for a particular style of processing, one fundamental question that is relevant to how individuals navigate their immediate environment is whether one style of processing is more or less dominant than the other. If people imagine a vacation or a trip, they might think visually and generate mental images based on what they have seen. If, on the other hand, they think of how to frame an argument, the thoughts might be more likely to be verbal (i.e., they might involve inner speech with words and sentences). However, is one style of processing more common than the other?

Amit, Hoeflin, Hamzah, and Fedorenko (2017) conducted studies to determine whether one could engage a specific modality (i.e., visualize or verbalize) without invoking the other unintentionally. Participants in their study were first trained to recall a series of engaging sentences and images using a cue. Brain regions that were scanned using a fMRI machine while they were doing so showed that people had robust verbal representations during inner speech, but they tended to generate visual images regardless of whether they intended to visualize or think verbally. However, when participants tried to think visually, there were only low levels of activity in the visual region. This suggests that visual processing might be more spontaneous and the tendency to form images (albeit somewhat impoverished ones) might be fairly innate (see Wyer, 2004 for a review on when mental images might be generated).

\section{5 | CONCLUDING REMARKS}

The literature on visual perception is large. Almost everything we see (text, pictures, static and moving objects, scenery) is visual and it is difficult to circumscribe and draw boundaries to include or exclude topics. This review is by no means exhaustive. Rather, it is representative of two broad areas of visual perception: processes and effects that are associated with the identification and recognition of objects (object processing) and processes and effects that are associated with the spatial location and transformation of objects (spatial processing). In the first major section of the review on object processing, only the representative areas of color, shape, logos, aesthetic elements, and visual and verbal information were included because they represented different features of the objects consumers encounter in marketing. In the second section of the review on spatial processing, dynamic aspects of visual perception were considered. That is, visual inputs emanating from objects were examined in relation to the perceiver and the ability to transform this visual input into a mental image to assist in some goal was discussed.

A few key themes emerge from the literature that was reviewed. First, the stimuli that consumers are exposed to (e.g., branded products, bill boards, store environments, and advertising) are not very different from what an individual might encounter routinely. Yet, many of these stimuli are manipulated strategically to influence the consumer. For example, color might be used to elicit certain feelings. And, even though the color green in the real environment is considered soothing and is associated with nature, in a marketing context it acquires a different connotation (i.e., is associated with money). The creation of these additional associations affects how 
consumers respond to marketing communications so that, at times, the same color might yield very different effects. A similar pattern is seen with shapes. Consumers have certain inherent preferences for shapes (e.g., the golden ratio). Yet, unusual and unique shapes that deviate from these inherent preferences are associated with rarity, and might be considered a good buy. Thus, marketing stimuli have, over time, widened the meaning ascribed to some of these features.

Second, many of the effects reviewed in the section on object processing result from top-down processes where prior cognitions affect how a visual stimulus is perceived. Thus, the appropriateness of a particular design esthetic might be considered in the context of past associations people have in memory (e.g., this is appropriate for a formal occasion). Or, the preference for art on a soap dish might arise from connotations of luxury that are made accessible upon exposure to art. Even, something as basic as color perception is affected by prior exposure to light and colors. Thus, it does appear that object processing is seen through the lens of our past experiences. But, at the same time, marketing actions enable the creation of new associations.

Third, spatial processing provides an assessment of where these objects are in relation to the perceiver. These "objects" include products but also other marketing stimuli (e.g., shopping carts, advertising, coupons). Much of this information about location and movement is processed spontaneously. However, what is crucial is the ability that individuals have to manipulate these symbols (or the visual signals they receive) to suit their own specific goals. Mere perception of these objects is not sufficient as consumers have to transform them using mental images in order to navigate the environment. Such imagery-based transformations can occur almost spontaneously in the course of comprehension or at will (e.g., when consumers use imagery to simulate a consumption scenario).

It is worth considering these themes in light of the theoretical perspectives outlined earlier, and the two systems that aid in visual perception. Both the theories of visual perception (constructivist and ecological) and the two visual systems (ventral and dorsal) are closely aligned with object and spatial processing. The research referenced in this review falls naturally into these sections as in the course of processing visual information related to marketing one has to understand what the products are (object processing) and how to get them (spatial processing). It is important to note that neither type of processing (object or spatial) is more important. Identifying things as they come into focus and reacting to them requires a dance where the two systems move in synchrony to help individuals navigate their world. Research in consumer behavior has fortuitously fallen in line with the dance steps of these two partners, and this review highlights how these two disparate yet related areas might be linked.

\section{ORCID}

Rashmi Adaval iD http://orcid.org/0000-0001-5206-934X

\section{REFERENCES}

Adaval, R. (2018). From doubt to functionality: An imagery story. Foundations and Trends in Marketing, 11(2), 73-142. https://doi. org/10.1561/1700000044

Adaval, R., Isbell, L. M., \& Wyer, R. S. Jr. (2007). The impact of pictures on narrative-and list-based impression formation: A process interference model. Journal of Experimental Social Psychology, 43(3), 352364. https://doi.org/10.1016/j.jesp.2006.04.005

Adaval, R., \& Wyer, R. S. Jr. (1998). The role of narratives in consumer information processing. Journal of Consumer Psychology, 7, 207-245. https://doi.org/10.1207/s15327663jcp0703_01

Adaval, R., \& Wyer, R. S. Jr. (2004). Communicating about a social interaction: Effects on memory for protagonists' statements and nonverbal behaviors. Journal of Experimental Social Psychology, 40(4), 450-465. https://doi.org/10.1016/j.jesp.2003.08.001

Alesandrini, K. L. (1981). Pictorial-verbal and analytic-holistic learning strategies in science learning. Journal of Educational Psychology, 73(3), 358-368. https://doi.org/10.1037/0022-0663.73.3.358

Amit, E., Hoeflin, C., Hamzah, N., \& Fedorenko, E. (2017). An asymmetrical relationship between verbal and visual thinking: Converging evidence from behavior and fMRI. Neurolmage, 152, 619-627. https:// doi.org/10.1016/j.neuroimage.2017.03.029

Atalay, A. S., Bodur, H. O., \& Rasolofoarison, D. (2012). Shining in the center: Central gaze cascade effect on product choice. Journal of Consumer Research, 39, 848-866. https://doi.org/10.1086/665984

Aydınoğlu, N. Z., \& Cian, L. (2014). Show me the product, show me the model: Effect of picture type on attitudes toward advertising. Journal of Consumer Psychology, 24, 506-519.

Aydinoğlu, N. Z., \& Krishna, A. (2012). Imagining thin: Why vanity sizing works. Journal of Consumer Psychology, 22, 565-572. https://doi. org/10.1016/j.jcps.2011.12.001

Babin, L. A., \& Burns, A. C. (1997). Effects of print ad pictures and copy containing instructions to imagine on mental imagery that mediates attitudes. Journal of Advertising, 26, 33-44. https://doi.org/10.1080/ 00913367.1997.10673527

Bagchi, R., \& Cheema, A. (2013). The effect of red background color on willingness-to-pay: The moderating role of selling mechanism. Journal of Consumer Research, 39, 947-960. https://doi. org/10.1086/666466

Bagozzi, R. P. (2008). Some insights on visual and verbal processing strategies. Journal of Consumer Psychology, 18, 258-263. https://doi. org/10.1016/j.jcps.2008.09.003

Bartlett, F. C. (1932). Remembering: An experimental and social study. Cambridge, UK: Cambridge University Press.

Bartolomeo, P. (2002). The relationship between visual perception and visual mental imagery: A reappraisal of the neuropsychological evidence. Cortex, 38(3), 357-378. https://doi.org/10.1016/ S0010-9452(08)70665-8

Behrmann, M., Winocur, G., \& Moscovitch, M. (1992). Dissociation between mental imagery and object recognition in a braindamaged patient. Nature, 359(6396), 636-637. https://doi. org/10.1038/359636a0

Benjafield, J. (1976). The 'golden rectangle': Some new data. The American Journal of Psychology, 89, 737-743. https://doi.org/10.2307/1421471

Bennett, B. M., Hoffman, D. D., \& Prakash, C. (1989). Observer mechanics: A formal theory of perception. San Diego, CA: Academic Press.

Bennett, B. M., Hoffman, D. D., \& Prakash, C. (1991). Unity of perception. Cognition, 38, 295-334. https://doi.org/10.1016/0010-0277(91)90009-S

Bisiach, E., \& Luzzatti, C. (1978). Unilateral neglect of representational space. Cortex, 14(1), 129-133. https://doi.org/10.1016/ S0010-9452(78)80016-1

Black, J. B., Turner, T. J., \& Bower, G. H. (1979). Point of view in narrative comprehension, memory, and production. Journal of Verbal Learning and Verbal Behavior, 18(2), 187-198. https://doi.org/10.1016/ S0022-5371(79)90118-X 
Blazhenkova, O., \& Kozhevnikov, M. (2010). Visual-object ability: A new dimension of non-verbal intelligence. Cognition, 117(3), 276-301. https://doi.org/10.1016/j.cognition.2010.08.021

Boerman, S. C., Smit, E. G., \& van Meurs, L. (2011). Attention battle; the abilities of brand, visual, and text characteristics of the ad to draw attention versus the diverting power of the direct magazine context. In S. Okazaki (Ed.), Advances in advertising research: Breaking new ground in theory and practice, Vol. 2 (pp. 295-310). Wiesbaden, Germany: Gabler Verlag.

Bone, P. F., \& Ellen, P. S. (1992). The generation and consequences of communication-evoked imagery. Journal of Consumer Research, 19, 93-104. https://doi.org/10.1086/209289

Boring, E. G. (1946). The perception of objects. American Journal of Physics, 14(2), 99-107. https://doi.org/10.1119/1.1990807

Borst, G., \& Kosslyn, S. M. (2008). Visual mental imagery and visual perception: Structural equivalence revealed by scanning processes. Memory and Cognition, 36(4), 849-862. https://doi.org/10.3758/ MC.36.4.849

Borst, G., \& Kosslyn, S. M. (2010). Individual differences in spatial mental imagery. The Quarterly Journal of Experimental Psychology, 63(10), 2031-2050. https://doi.org/10.1080/17470211003802459

Buechel, E. C., \& Townsend, C. (2018). Buying beauty for the long run: (Mis) predicting liking of product aesthetics. Journal of Consumer Research, 45, 275-297. https://doi.org/10.1093/jcr/ucy002

Childers, T. L., \& Houston, M. J. (1984). Conditions for a picturesuperiority effect on consumer memory. Journal of Consumer Research, 11, 643-654. https://doi.org/10.1086/209001

Childers, T. L., Houston, M. J., \& Heckler, S. E. (1985). Measurement of individual differences in visual versus verbal information processing. Journal of Consumer Research, 12(2), 125-134. https://doi.org/10.1086/208501

Childers, T. L., \& Jass, J. (2002). All dressed up with something to say: Effects of typeface semantic associations on brand perceptions and consumer memory. Journal of Consumer Psychology, 12, 93-106. https://doi.org/10.1207/S15327663JCP1202_03

Cian, L., Krishna, A., \& Elder, R. S. (2014). This logo moves me: Dynamic imagery from static images. Journal of Marketing Research, 51, 184197. https://doi.org/10.1509/jmr.13.0023

Cian, L., Krishna, A., \& Elder, R. S. (2015). A sign of things to come: Behavioral change through dynamic iconography. Journal of Consumer Research, 41, 1426-1446. https://doi.org/10.1086/680673

Costley, C. L., \& Brucks, M. (1992). Selective recall and information use in consumer preferences. Journal of Consumer Research, 18, 464-474. https://doi.org/10.1086/209274

Edell, J. A., \& Staelin, R. (1983). The information processing of pictures in print advertisements. Journal of Consumer Research, 10, 45-61. https://doi.org/10.1086/208944

Elder, R. S., \& Krishna, A. (2012). The "visual depiction effect" in advertising: Facilitating embodied mental simulation through product orientation. Journal of Consumer Research, 38, 988-1003. https://doi. org/10.1086/661531

Elder, R. S., Schlosser, A. E., Poor, M., \& Xu, L. (2017). So close I can almost sense it: The interplay between sensory imagery and psychological distance. Journal of Consumer Research, 44, 877-894. https:// doi.org/10.1093/jcr/ucx070

Epstein, W. (1973). The process of "taking-into-account" in visual perception. Perception, 2(3), 67-85.

Epstein, W. (1995). The metatheoretical context. In W. Epstein, \& S. Rodgers (Eds.), Perception of space and motion (pp. 1-22). San Diego, CA: Academic Press.

Fajardo, T. M., Zhang, J., \& Tsiros, M. (2016). The contingent nature of the symbolic associations of visual design elements: The case of brand logo frames. Journal of Consumer Research, 43, 549-566. https://doi. org/10.1093/jcr/ucw048

Farah, M. J. (1989). The neural basis of mental imagery. Trends in Neurosciences, 12(10), 395-399. https://doi. org/10.1016/0166-2236(89)90079-9
Folkes, V., \& Matta, S. (2004). The effect of package shape on consumers' judgments of product volume: Attention as a mental contaminant. Journal of Consumer Research, 31, 390-401. https://doi.org/10.1086/422117

Freyd, J. J. (1983). The mental representation of movement when static stimuli are viewed. Perception and Psychophysics, 33(6), 575-581. https://doi.org/10.3758/BF03202940

Gibson, J. J. (1966). The senses considered as perceptual systems. Boston, MA: Houghton Mifflin.

Gibson, J. J. (1979). The ecological approach to visual perception. Boston, MA: Houghton Mifflin.

Gilchrist, A. L. (1977). Perceived lightness depends on perceived spatial arrangement. Science, 195(4274), 185-187. https://doi.org/10.1126/ science. 831266

Gilchrist, A. L. (1980). When does perceived lightness depend on perceived spatial arrangement? Perception and Psychophysics, 28(6), 527-538. https://doi.org/10.3758/BF03198821

Goebel, R., Khorram-Sefat, D., Muckli, L., Hacker, H., \& Singer, W. (1998). The constructive nature of vision: Direct evidence from functional magnetic resonance imaging studies of apparent motion and motion imagery. European Journal of Neuroscience, 10(5), 1563-1573. https:// doi.org/10.1046/j.1460-9568.1998.00181.x

Goldberg, J. H., Probart, C. K., \& Zak, R. E. (1999). Visual search of food nutrition labels. Human Factors, 41(3), 425-437. https://doi. org/10.1518/001872099779611021

Goodale, M. A., \& Milner, A. D. (1992). Separate visual pathways for perception and action. Trends in Neurosciences, 15(1), 20-25. https://doi. org/10.1016/0166-2236(92)90344-8

Gorn, G. J., Chattopadhyay, A., Sengupta, J., \& Tripathi, S. (2004). Waiting for the web: How screen color affects time perception. Journal of Marketing Research, 41(2), 215-225. https://doi.org/10.1509/ jmkr.41.2.215.28668

Gorn, G. J., Chattopadhyay, A., Yi, T., \& Dahl, D. W. (1997). Effects of color as an executional cue in advertising: They're in the shade. Management Science, 43(10), 1387-1400. https://doi.org/10.1287/ mnsc.43.10.1387

Green, K. E., \& Schroeder, D. H. (1990). Psychometric quality of the verbalizervisualizer questionnaire as a measure of cognitive style. Psychological Reports, 66(3), 939-945. https://doi.org/10.2466/pr0.1990.66.3.939

Greenleaf, E., \& Raghubir, P. (2008). Geometry in the marketplace. In M. Wedel, \& R. Pieters (Eds.), Visual marketing: From attention to action (pp. 113-142). New York, NY: Erlbaum.

Gregory, R. L. (1993). Seeing and thinking. Giornale Italiano di Psicologia, 20(5), 749-769.

Haber, R. N. (1985). Perception - A one-hundred-year perspective. In S. Koch, \& D. E. Leary (Eds.), A century of psychology as science (pp. 224-230). New York, NY: McGraw-Hill.

Hagtvedt, H. (2011). The impact of incomplete typeface logos on perceptions of the firm. Journal of Marketing, 75, 86-93. https://doi. org/10.1509/jmkg.75.4.86

Hagtvedt, H., \& Brasel, S. A. (2016). Cross-modal communication: Sound frequency influences consumer responses to color lightness. Journal of Marketing Research, 53, 551-562. https://doi.org/10.1509/ jmr.14.0414

Hagtvedt, H., \& Brasel, S. A. (2017). Color saturation increases perceived product size. Journal of Consumer Research, 44, 396-413.

Hagtvedt, H., \& Patrick, V. M. (2008a). Art and the brand: The role of visual art in enhancing brand extendibility. Journal of Consumer Psychology, 18, 212-222. https://doi.org/10.1016/j.jcps.2008.04.010

Hagtvedt, H., \& Patrick, V. M. (2008b). Art infusion: The influence of visual art on the perception and evaluation of consumer products. Journal of Marketing Research, 45, 379-389. https://doi.org/10.1509/ jmkr.45.3.379

Hatfield, G. (1988). Representation and content in some (actual) theories of perception. Studies in History and Philosophy of Science Part A, 19(2), 175-214. https://doi.org/10.1016/0039-3681(88)90026-X 
Hatfield, G. (1990). Gibsonian representations and connectionist symbol processing: Prospects for unification. Psychological Research, 52(2-3), 243-252. https://doi.org/10.1007/BF00877533

Heckler, S. E., \& Childers, T. L. (1992). The role of expectancy and relevancy in memory for verbal and visual information: What is incongruency? Journal of Consumer Research, 18, 475-492. https://doi. org $/ 10.1086 / 209275$

Henderson, P. W., \& Cote, J. A. (1998). Guidelines for selecting or modifying logos. The Journal of Marketing, 62, 14-30. https://doi. org/10.2307/1252158

Henderson, P. W., Cote, J. A., Leong, S. M., \& Schmitt, B. (2003). Building strong brands in Asia: Selecting the visual components of image to maximize brand strength. International Journal of Research in Marketing, 20, 297-313. https://doi.org/10.1016/j. ijresmar.2003.03.001

Henderson, P. W., Giese, J. L., \& Cote, J. A. (2004). Impression management using typeface design. Journal of Marketing, 68, 60-72. https:// doi.org/10.1509/jmkg.68.4.60.42736

Hoegg, J., Alba, J. W., \& Dahl, D. W. (2010). The good, the bad, and the ugly: Influence of aesthetics on product feature judgments. Journal of Consumer Psychology, 20, 419-430. https://doi.org/10.1016/j. jcps.2010.07.002

Holway, A. H., \& Boring, E. G. (1941). Determinants of apparent visual size with distance variant. American Journal of Psychology, 54, 21-37. https://doi.org/10.2307/1417790

Houston, M. J., Childers, T. L., \& Heckler, S. E. (1987). Pictureword consistency and the elaborative processing of advertisements. Journal of Marketing Research, 24, 359-369. https://doi. org $/ 10.2307 / 3151383$

Huh, Y. E., Vosgerau, J., \& Morewedge, C. K. (2016). Selective sensitization: Consuming a food activates a goal to consume its complements. Journal of Marketing Research, 53(6), 1034-1049. https://doi. org $/ 10.1509 /$ jmr.12.0240

Hung, I. W., \& Wyer, R. S. Jr. (2011). Shaping consumer imaginations: The role of self-focused attention in product evaluations. Journal of Marketing Research, 48, 381-392. https://doi.org/10.1509/ jmkr.48.2.381

Ingle, D. (1973). Two visual systems in the frog. Science, 181, 1053-1055. https://doi.org/10.1126/science.181.4104.1053

Janiszewski, C. (1998). The influence of display characteristics on visual exploratory search behavior. Journal of Consumer Research, 25, 290301. https://doi.org/10.1086/209540

Janiszewski, C., \& Meyvis, T. (2001). Effects of brand logo complexity, repetition, and spacing on processing fluency and judgment. Journal of Consumer Research, 28, 18-32. https://doi. org $/ 10.1086 / 321945$

Jeannerod, M. (1997). The cognitive neuroscience of action. Cambridge, MA: Blackwell.

Jia, Y., Huang, Y., Wyer, R. S. Jr., \& Shen, H. (2017). Physical proximity increases persuasive effectiveness through visual imagery. Journal of Consumer Psychology, 27, 435-447. https://doi.org/10.1016/j. jcps.2017.07.001

Jiang, Y., Adaval, R., Steinhart, Y., \& Wyer, R. S. Jr. (2014). Imagining yourself in the scene: The interactive effects of goal-driven self-imagery and visual perspectives on consumer behavior. Journal of Consumer Research, 41, 418-435. https://doi.org/10.1086/676966

Jiang, Y., Gorn, G. J., Galli, M., \& Chattopadhyay, A. (2016). Does your company have the right logo? How and why circular-and angular-logo shapes influence brand attribute judgments. Journal of Consumer Research, 42, 709-726. https://doi.org/10.1093/jcr/ ucv049

Jiang, Y., Steinhart, Y., \& Wyer, R. S. (2007). The role of visual and semantic processing strategies in consumer information processing. Unpublished manuscript, Hong Kong University of Science and Technology.
Jiang, Y., \& Wyer, R. S. Jr. (2009). The role of visual perspective in information processing. Journal of Experimental Social Psychology, 45(3), 486-495. https://doi.org/10.1016/j.jesp.2008.12.006

Johansson, G. (1950). Configurations in event perception. Uppsala, Sweden: Almkvist and Wiksell.

Kourtzi, Z., \& Kanwisher, N. (2000). Activation in human MT/MST by static images with implied motion. Journal of Cognitive Neuroscience, 12(1), 48-55. https://doi.org/10.1162/08989290051137594

Kozhevnikov, M., Blazhenkova, O., \& Becker, M. (2010). Trade-off in object versus spatial visualization abilities: Restriction in the development of visual-processing resources. Psychonomic Bulletin and Review, 17(1), 29-35. https://doi.org/10.3758/PBR.17.1.29

Kozhevnikov, M., Kosslyn, S., \& Shephard, J. (2005). Spatial versus object visualizers: A new characterization of visual cognitive style. Memory and Cognition, 33(4), 710-726. https://doi.org/10.3758/ BF03195337

Krider, R. E., Raghubir, P., \& Krishna, A. (2001). Pizzas: $\pi$ or square? Psychophysical biases in area comparisons. Marketing Science, 20(4), 405-425. https://doi.org/10.1287/mksc.20.4.405.9756

Krishna, A., Morrin, M., \& Sayin, E. (2014). Smellizing cookies and salivating: A focus on olfactory imagery. Journal of Consumer Research, 41, 18-34. https://doi.org/10.1086/674664

Kumar, M., \& Garg, N. (2010). Aesthetic principles and cognitive emotion appraisals: How much of the beauty lies in the eye of the beholder? Journal of Consumer Psychology, 20, 485-494. https://doi. org/10.1016/j.jcps.2010.06.015

Lee, H., Deng, X., Unnava, H. R., \& Fujita, K. (2014). Monochrome forests and colorful trees: The effect of black-and-white versus color imagery on construal level. Journal of Consumer Research, 41, 1015-1032. https://doi.org/10.1086/678392

Lee, N. Y., Noble, S. M., \& Biswas, D. (2018). Hey big spender! A golden (color) atmospheric effect on tipping behavior. Journal of the Academy of Marketing Science, 46, 317-337. https://doi.org/10.1007/ s11747-016-0508-3

Mandel, N., \& Johnson, E. J. (2002). When web pages influence choice: Effects of visual primes on experts and novices. Journal of Consumer Research, 29, 235-245. https://doi.org/10.1086/341573

Mandel, N., Petrova, P. K., \& Cialdini, R. B. (2006). Images of success and the preference for luxury brands. Journal of Consumer Psychology, 16, 57-69. https://doi.org/10.1207/s15327663jcp1601_8

Marks, D. F. (1973). Visual imagery differences in the recall of pictures. British Journal of Psychology, 64(1), 17-24. https://doi. org/10.1111/j.2044-8295.1973.tb01322.x

McManus, I. C. (1980). The aesthetics of simple figures. British Journal of Psychology, 71(4), 505-524. https://doi. org/10.1111/j.2044-8295.1980.tb01763.x

Mehta, R., Demmers, J., van Dolen, W. M., \& Weinberg, C. B. (2017). When red means go: Non-normative effects of red under sensation seeking. Journal of Consumer Psychology, 27, 91-97. https://doi. org/10.1016/j.jcps.2016.04.004

Meyers-Levy, J., \& Peracchio, L. A. (1995). Understanding the effects of color: How the correspondence between available and required resources affects attitudes. Journal of Consumer Research, 22, 121-138. https://doi.org/10.1086/209440

Michaels, C. F., \& Carello, C. (1981). Direct perception. Englewood Cliffs, NJ: Prentice-Hall.

Milner, A. D., \& Goodale, M. A. (1995). The visual brain in action. Oxford, UK: Oxford University Press.

Miniard, P. W., Bhatla, S., Lord, K. R., Dickson, P. R., \& Unnava, H. R. (1991). Picture-based persuasion processes and the moderating role of involvement. Journal of Consumer Research, 18, 92-107. https://doi. org/10.1086/209244

Moro, V., Berlucchi, G., Lerch, J., Tomaiuolo, F., \& Aglioti, S. M. (2008). Selective deficit of mental visual imagery with intact primary visual 
cortex and visual perception. Cortex, 44(2), 109-118. https://doi. org/10.1016/j.cortex.2006.06.004

Neisser, U. (1994). Multiple systems: A new approach to cognitive theory. European Journal of Cognitive Psychology, 6(3), 225-241. https://doi. org/10.1080/09541449408520146

Norman, J. (2002). Two visual systems and two theories of perception: An attempt to reconcile the constructivist and ecological approaches. Behavioral and Brain Sciences, 25(1), 73-96.

Noseworthy, T. J., Cotte, J., \& Lee, S. H. (2011). The effects of ad context and gender on the identification of visually incongruent products. Journal of Consumer Research, 38, 358-375. https://doi. org/10.1086/658472

O'Craven, K. M., \& Kanwisher, N. (2000). Mental imagery of faces and places activates corresponding stimulus-specific brain regions. Journal of Cognitive Neuroscience, 12, 1013-1023. https://doi. org/10.1162/08989290051137549

Paivio, A. (1971). Imagery and language. In S. J. Segal (Ed.), Imagery: Current cognitive approaches (pp. 7-32). New York, NY: Academic Press. https://doi.org/10.1016/B978-0-12-635450-8.50008 $-X$

Paivio, A. (1977). Images, propositions, and knowledge. In J. M. Nicholas (Ed.), Images, perception, and knowledge. The Western Ontario series in philosophy of science (pp. 47-71). Dordrecht, Holland: Reidel.

Peschel, A. O., \& Orquin, J. L. (2013). A review of the findings and theories on surface size effects on visual attention. Frontiers in Psychology, $4,902$.

Petrova, P. K., \& Cialdini, R. B. (2005). Fluency of consumption imagery and the backfire effects of imagery appeals. Journal of Consumer Research, 32, 442-452. https://doi.org/10.1086/497556

Pham, M. T., Meyvis, T., \& Zhou, R. (2001). Beyond the obvious: Chronic vividness of imagery and the use of information in decision making. Organizational Behavior and Human Decision Processes, 84, 226-253. https://doi.org/10.1006/obhd.2000.2924

Piehl, J. (1978). The golden section: The "true" ratio? Perceptual and Motor Skills, 46(3), 831-834. https://doi.org/10.2466/ pms.1978.46.3.831

Pieters, R., \& Warlop, L. (1999). Visual attention during brand choice: The impact of time pressure and task motivation. International Journal of Research in Marketing, 16(1), 1-16. https://doi.org/10.1016/ S0167-8116(98)00022-6

Pieters, R., \& Wedel, M. (2004). Attention capture and transfer in advertising: Brand, pictorial, and text-size effects. Journal of Marketing, 68(2), 36-50. https://doi.org/10.1509/jmkg.68.2.36.27794

Pieters, R., Wedel, M., \& Batra, R. (2010). The stopping power of advertising: Measures and effects of visual complexity. Journal of Marketing 74(5), 48-60. https://doi.org/10.1509/jmkg.74.5.48

Pieters, R., Wedel, M., \& Zhang, J. (2007). Optimal feature advertising design under competitive clutter. Management Science, 53(11), 18151828. https://doi.org/10.1287/mnsc.1070.0732

Plug, C. (1976). The psychology of superstition: A review. Psychologia Africana, 16, 93-115.

Raghubir, P., \& Greenleaf, E. A. (2006). Ratios in proportion: What should the shape of the package be? Journal of Marketing, 70, 95-107. https://doi.org/10.1509/jmkg.70.2.95

Raghubir, P., \& Krishna, A. (1999). Vital dimensions in volume perception: Can the eye fool the stomach? Journal of Marketing Research, 36 313-326. https://doi.org/10.2307/3152079

Rahinel, R., \& Nelson, N. M. (2016). When brand logos describe the environment: Design instability and the utility of safety-oriented products. Journal of Consumer Research, 43, 478-496. https://doi. org/10.1093/jcr/ucw039

Reimann, M., Zaichkowsky, J., Neuhaus, C., Bender, T., \& Weber, B. (2010). Aesthetic package design: A behavioral, neural, and psychological investigation. Journal of Consumer Psychology, 20, 431-441. https://doi.org/10.1016/j.jcps.2010.06.009
Richardson, A. (1977). The meaning and measurement of memory imagery. British Journal of Psychology, 68(1), 29-43. https://doi. org/10.1111/j.2044-8295.1977.tb01556.x

Rock, I. (1977). In defense of unconscious inference. In W. Epstein (Ed.), Stability and constancy in visual perception: Mechanisms and processes (pp. 321-373). New York, NY: Wiley.

Rock, I. (1983). The logic of perception. Cambridge, MA: MIT Press.

Rock, I. (Ed.) (1997). Indirect perception. Cambridge, MA: MIT Press.

Rosbergen, E., Pieters, R., \& Wedel, M. (1997). Visual attention to advertising: A segment-level analysis. Journal of Consumer Research, 24(3), 305-314. https://doi.org/10.1086/209512

Schlosser, A. E. (2006). Learning through virtual product experience: The role of imagery on true versus false memories. Journal of Consumer Research, 33, 377-383. https://doi.org/10.1086/508522

Schneider, G. E. (1967). Contrasting visuomotor functions of tectum and cortex in the Golden Hamster. Psychologische Forschung, 31(1), 5262. https://doi.org/10.1007/BF00422386

Schneider, G. E. (1969). Two visual systems. Science, 163(3870), 895-902. https://doi.org/10.1126/science.163.3870.895

Si, K., \& Jiang, Y. (2017). Bidirectional contrast effects between taste perception and simulation: A simulation-induced adaptation mechanism. Journal of Consumer Psychology, 27(1), 49-58. https://doi. org/10.1016/j.jcps.2016.04.002

Svensson, L. T. (1977). Note on the golden section. Scandinavian Journal of Psychology, 18(1), 79-80. https://doi.org/10.1111/j.1467-9450.1977. tb00259.x

Thompson, D. V., \& Hamilton, R. W. (2006). The effects of information processing mode on consumers' responses to comparative advertising. Journal of Consumer Research, 32, 530-540. https://doi. org/10.1086/500483

Thompson, E., Palacios, A., \& Varela, F. J. (1992). On the ways to color. Behavioral and Brain Sciences, 15(1), 56-74. https://doi.org/10.1017/ S0140525X00067583

Titchener, E. B. (1914). A textbook of psychology. New York, NY: Macmillan.

Townsend, C. (2017). The price of beauty: Differential effects of design elements with and without cost implications in nonprofit donor solicitations. Journal of Consumer Research, 44, 794-815. https://doi. org/10.1093/jcr/ucx059

Townsend, C., \& Shu, S. B. (2010). When and how aesthetics influences financial decisions. Journal of Consumer Psychology, 20, 452-458. https://doi.org/10.1016/j.jcps.2010.06.013

Townsend, C., \& Sood, S. (2012). Self-affirmation through the choice of highly aesthetic products. Journal of Consumer Research, 39, 415428. https://doi.org/10.1086/663775

Trevarthen, C. B. (1968). Two mechanisms of vision in primates. Psychologische Forschung, 31(4), 299-337. https://doi.org/10.1007/BF00422717

Unnava, H. R., \& Burnkrant, R. E. (1991). An imagery-processing view of the role of pictures in print advertisements. Journal of Marketing Research, 28, 226-231. https://doi.org/10.2307/3172811

Valenzuela, A., \& Raghubir, P. (2009). Position-based beliefs: The centerstage effect. Journal of Consumer Psychology, 19, 185-196. https:// doi.org/10.1016/j.jcps.2009.02.011

Wallisch, P. (2017). Illumination assumptions account for individual differences in the perceptual interpretation of a profoundly ambiguous stimulus in the color domain: "The dress". Journal of Vision, 17(5), 1-14.

Wedel, M., \& Pieters, R. (2008). A review of eye-tracking research in marketing. In N. K. Malhotra (Ed.) Review of Marketing Research, Vol. 4 (pp. 123-147) Emerald Group Publishing Ltd.

Welbourne, L. E., Morland, A. B., \& Wade, A. R. (2015). Human color perception changes between seasons. Current Biology, 25(15), R646-R647. https://doi.org/10.1016/j.cub.2015.06.030

Wu, F., Samper, A., Morales, A. C., \& Fitzsimons, G. J. (2017). It's too pretty to use! When and how enhanced product aesthetics discourage usage and lower consumption enjoyment. Journal of 
Consumer Research, 44, 651-672. https://doi.org/10.1093/jcr/ ucx057

Wyer, R. S. Jr. (2004). Social comprehension and judgment: The role of situation models, narratives, and implicit theories. Mahwah, NJ: Lawrence Erlbaum.

Wyer, R. S. Jr., \& Adaval, R. (2008). Social psychology and consumer psychology: An unexplored interface. In The social psychology of consumer behavior (Editor: Wänke, M., University of Basel, Switzerland). Frontiers of Social Psychology (Series Editors: Kruglanski A. W \& Forgas, J. P). New York: Psychology Press

Wyer, R. S. Jr., Hung, I. W., \& Jiang, Y. (2008). Visual and verbal processing strategies in comprehension and judgment. Journal of Consumer Psychology, 18(4), 244-257. https://doi.org/10.1016/j. jcps.2008.09.002

Wyer, R. S. Jr., Jiang, Y., \& Hung, I. W. (2008). Visual and verbal information processing in a consumer context: Further considerations. Journal of Consumer Psychology, 18(4), 276-280. https://doi. org/10.1016/j.jcps.2008.09.005
Yang, S., \& Raghubir, P. (2005). Can bottles speak volumes? The effect of package shape on how much to buy. Journal of Retailing, 81, 269-281. https://doi.org/10.1016/j.jretai.2004.11.003

Zhao, M., Dahl, D. W., \& Hoeffler, S. (2014). Optimal visualization aids and temporal framing for new products. Journal of Consumer Research, 41, 1137-1151. https://doi.org/10.1086/678485

How to cite this article: Adaval R, Saluja G, Jiang Y. Seeing and thinking in pictures: A review of visual information processing. Consum Psychol Rev. 2018;00:1-20. https://doi. org/10.1002/arcp.1049 